\title{
Halloysite nanotubes functionalized with epoxy and thiol organosilane groups to improve fracture toughness in nanocomposites
}

\author{
Zachary Murphy $^{1} \cdot$ Malachi Kent $^{1} \cdot$ Christian Freeman $^{1} \cdot$ Shainaz Landge $^{1} \cdot$ Ermias Koricho $^{2}$ (i)
}

Received: 30 August 2020 / Accepted: 18 November 2020 / Published online: 2 December 2020

(c) Springer Nature Switzerland AG 2020

\begin{abstract}
The surface functionalization of nanofillers imbibed within the matrix provides great interfacial adhesion with the epoxy resin and as such, in this study, the pure and functionalized halloysite nanotubes (HNTs) were used as fillers to improve the fracture toughness of an SC-15 epoxy resin. The HNTs were grafted with an organosilane group having terminal epoxy and thiol functional groups as two different crosslinkers and were thoroughly characterized with infrared spectroscopy (IR), scanning electron microscope (SEM), energy dispersive X-ray spectroscopy (EDS), powder X-ray diffraction (PXRD), and thermogravimetric analysis (TGA). The nanocomposites resulting from these fillers were used in compact tension (CT) testing with varying weight $\%$ from 0 to $2 \%$, which were then fabricated and tested as per ASTM D5045 standard to evaluate the fracture toughness. The critical stress intensity factor $\left(\mathrm{K}_{\mathrm{IC}}\right)$ and the critical strain energy release rate $\left(\mathrm{G}_{\mathrm{IC}}\right)$ were measured, and a correlation was established between the test results and the mode of fractured surface images obtained by the SEM. Experimental results showed that the synergistic effect was observed with the addition of HNTs nanofillers into the SC-15 epoxy. The highest improved $\mathrm{K}_{\mathrm{IC}}$ and $\mathrm{G}_{\mathrm{IC}}$ were achieved using $2 \%$ HNT-thiol, followed by $2 \%$ pure HNT, and 1\% HNT-epoxy nanofillers, respectively. SEM observation further confirmed that the presence of pure and functionalized HNT in the SC-15 epoxy matrix changed the toughness mechanics from smooth and low pseudo-ductile to several energy absorption mechanisms such as fibrils, river liner, crack bridging, crazing, microvoids, and hackles.
\end{abstract}

Keywords Halloysite · Nanocomposites - Epoxy · Functionalized nanotubes · Physicochemical · Compact tension · Fracture toughness · Energy absorption · Morphology

\section{Introduction}

Understanding the mechanical behavior of composite materials for energy absorbing applications such as vehicle crashworthiness, impact resistance devices, and personal protective equipment has gained significant attention from researchers [1]. Particularly, thermosetting polymers have become a prominent research area due to their unique properties, such as stability under high temperatures, high mechanical strength, viscoelastic properties, and resistant to solvent. However, thermosets have a network of covalently bonded macromolecular structure, with a high crosslink density and little dissipated energy. i.e., plastic deformation in front of the crack tip is localized, which leads to a catastrophic brittle failure [1-4]. Hence, more efforts have been placed to improve the fracture toughness and alter the failure mechanism in the fracture process zone of thermoset polymers [4-10].

Research has been focused on nanofillers and the resulting nanocomposite polymers to further improve

\footnotetext{
$\triangle$ Shainaz Landge, slandge@georgiasouthern.edu; $\bowtie$ Ermias Koricho, ekoricho@georgiasouthern.edu| ${ }^{1}$ Department of Chemistry and Biochemistry, 521, College of Education Drive, Statesboro, GA, USA. ${ }^{2}$ Department of Mechanical Engineering, Georgia Southern University, P.O. Box 8046, Statesboro, GA, USA.
} 
the fracture toughness of nanocomposite materials as compared with that of the commercially available materials (epoxy resin). It has been established that the incorporation of a second micro-phase of a dispersed rubber (core-shell rubber (CSR) particles) can be considered as a promising solution [4, 11-14]. These particles comprised of a soft rubbery core within a harder shell and are typically formed by emulsion polymerization, and then dispersed in the epoxy resin. These materials have shown to increase the toughness of both bulk polymers and fiber composites $[4,15-17]$. However, in general, the literature reports that the fracture toughness of rubber-toughened epoxy polymers is susceptible to temperature variation. On the other hand, to improve the mechanical properties, it is suggested that low or high aspect ratio fillers, such carbon nanotubes (CNT), HNTs, nanoclays, and graphene platelets can be incorporated into the epoxy [18-22]. These fillers possess higher rigidity than the base polymer [18], give high specific surface area [19], and provide sufficient fillermatrix bonding to improve strength and to allow a controlled stress transfer from the matrix to the fillers [23, 24]. HNTs in particular are also known for its energy dissipation and toughening mechanisms such as crack pinning and crack deflection [25].

Fillers, with preferably small dimensions, can reduce local stress concentrations and generate high toughness and impact resistance [20]. The reduction of the filler dimensions in brittle polymer composites, such as epoxybased composite, is a favorable direction to enhance the toughness since it will focus on improving the microstructural perfection of composites by minimizing the size of potential defects (e.g. inclusions, agglomerates, etc.).

Naturally occurring nanomaterials such as HNTs, kaolinite, and montmorillonite, are used in the fabrication of materials. Halloysite was also successfully employed as filler for macromolecules (such as polymers, proteins, resins) in order to obtain nanocomposite materials for cosmetics [26], packaging [27], and restoration [28] applications. They have commonly been functionalized with organosilane groups to increase the thermal and mechanical characteristics of the composite materials [29-31]. The organosilane agents and the hydroxyl groups of nanomaterials can be covalently bonded thus allowing to finetune the surface of the clays for enhanced reactivity and prevent leaching [32,33].

Particularly, halloysite nanotubes are commercially available, inexpensive, and have a tubular structure with siloxy groups on the external surface, and aluminol groups on the inner lumen $[34,35]$. These external siloxy groups allow for the facile attachment of organosilanes. HNT with its molecular formula $\left(\mathrm{Al}_{2} \mathrm{Si}_{2} \mathrm{O}_{5}(\mathrm{OH})_{4} \cdot 2 \mathrm{H}_{2} \mathrm{O}\right)$ has an inner diameter of 1-30 $\mathrm{nm}$ and an external diameter of 30-70 nm [36-40]. Its characteristic dimensional structure is made by tetrahedral and octahedral building blocks; it forms a very specific nanoscale lumen with better length to diameter $(\mathrm{l} / \mathrm{d})$ ratio and can be well utilized in the preparation of nanocomposites. These distinct features indicate the potential of HNTs as a filler for this study. HNTs are also a logical alternative to CNTs because they are cheaper, naturally found, and eco-friendlier. Once functionalized, many material characteristics can be targeted and be significantly improved [41, 42].

There is a gap in the literature that needs to be filled when it comes to studying the fracture toughness of the material. The epoxy resin which is generally used is limited in advanced applications such as adhesives and fiber-reinforced materials due to its intrinsic brittleness. To improve the toughness of the material many epoxy resins are modified via the addition of different fillers which can be covalently bonded to organic materials, inorganic materials, core-shell rubber (CRS) nanoparticles etc. [12, 20, 43, 44].

This study focused on improving the fracture toughness of the existing SC-15 epoxy resin, a two-part toughened epoxy, by incorporating functionalized HNTs as fillers. The pristine HNTs were functionalized with epoxy and thiol functional groups (Scheme 1). The terminal epoxy and thiol functional groups were explored because of their easy reactivity with other organic molecules or ligands. This characteristic makes them preferred coupling agents [45], while generally retaining the beneficial base properties already present in the nanotubes [46].

The effect of HNTs on the chemical composition and thermal properties of the resulting nanocomposites were evaluated by physicochemical characterization. The compact tension (CT) testing was conducted to investigate the influence of pure and functionalized HNTs on the fracture toughness of SC-15 epoxy resin in terms of $K_{I C}$ and $G_{I C}$. Morphology analysis was also performed used a Field Emission Scanning Electron Microscopy (FESEM) to evaluate the effect of nanomodification on the failure mechanisms of nanocomposites.

\section{Materials and methods}

\subsection{Materials}

Halloysite nanotube (HNT), (with 30-70 nm outer diameter; $1-3 \mu \mathrm{m}$ in length and surface area of $64 \mathrm{~m}^{2} / \mathrm{g}$ ) were purchased from Sigma Aldrich. Glacial acetic acid, HPLC grade toluene, and methanol were purchased by Fisher Scientific. The following organosilane, (3-Glycidyloxypropyl) trimethoxysilane (GLYMO) was bought from Tokyo Chemical Industry Co., Ltd. and (3-mercaptopropyl) triethoxysilane (MEPES) (94\%), organosilanes were purchased from Alfa Aesar and were both used as coupling agents. 


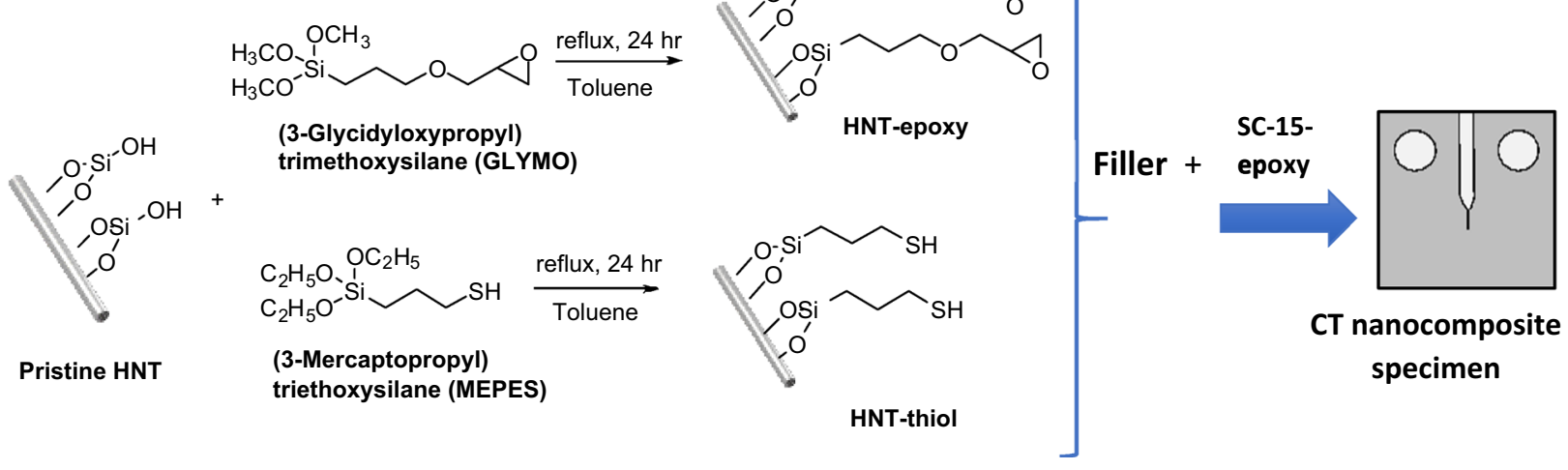

Scheme 1 General Scheme showing the pure HNTs reaction with organosilane (GLYMO and MEPES) groups to synthesized modified HNTs, which are incorporated as fillers with SC-15 epoxy in Compact Tension (CT) Testing nanocomposite specimen

All reactants/reagents were used as purchased with no further purification. The resin used was a two-part toughened epoxy, namely SC-15 was obtained from Applied Poleramic.

\subsection{Functionalization of HNT with organosilane group}

HNT was pre-dried in a vacuum oven overnight. In a general reaction, $2.0 \mathrm{~g}$ of HNT was suspended and stirred in $20 \mathrm{~mL}$ toluene. The desired organosilane (GLYMO or MEPES; 3 M equivalent) was added dropwise. The solution was sonicated for 10-15 min with occasional stirring. The mixture was further sonicated for 10 more minutes with intermittent stirring. This slurry was then refluxed for $24 \mathrm{~h}$ at $120^{\circ} \mathrm{C}$, the final resultant powder was vacuum filtered and rinsed thoroughly with mixed solvents such as methanol and toluene. The product was then dried overnight in a vacuum oven, and fully characterized via TGA, FTIR, PXRD, SEM, EDS Then, the functionalized nanofillers were incorporated in SC-15 epoxy resin to manufacture the CT specimens, as shown in Scheme 1.

\subsection{Manufacturing of nanocomposite}

Part A of SC-15 epoxy was mixed with the desired concentration $(0 \%, 0.5 \%, 1 \%$, and $2 \%)$ of functionalized halloysite and the resulting material was mixed using a magnetic stirrer, followed by ultrasonication for around $30 \mathrm{~min}$. Intermittent sonicating energy (10 s energy, $5 \mathrm{~s}$ pause) was applied to control the rise in temperature of the compound. The resulting mixture was cooled at room temperature for $30 \mathrm{~min}$, followed by the addition of part $\mathrm{B}$ of the SC-15 epoxy. The solution was degassed for $20 \mathrm{~min}$ and then poured into pre-prepared silicone molds to manufacture the $\mathrm{CT}$ specimens. Curing was completed in a convection oven at $60^{\circ} \mathrm{C}$ for $2 \mathrm{~h}$ and post-cured at $94^{\circ} \mathrm{C}$ for $4 \mathrm{~h}$. The specimens were removed from the mold and milled and polished to the desired thickness, as specified in Fig. 1, as per ASTM D5045 standard. A sharp pre-crack was introduced using a razor blade and care was taken to obtain the same pre-crack lengths for all specimens.

\subsection{Fracture toughness test}

To study the effect of inclusion of the halloysite nanotube based nanofillers on the fracture toughness of the SC-15 epoxy, five composites were prepared for each test configuration as per ASTM standard, D 5045, as shown in Fig. 1. The CT testing was performed using Mark 10-M5-300, as shown in Fig. 2 at a speed of $0.02 \mathrm{~mm}$ per minute. The deformation was monitored and analyzed in video recording using a digital camera to provide further information about crack initiation and propagation. The software program used by the Mark 10- M5-300, MESUR, recorded the force and the crack opening displacement until the specimen broke. The collected data was then used to calculate the critical stress intensity factor $\left(\mathrm{K}_{\mathrm{IC}}\right)$ and the critical strain

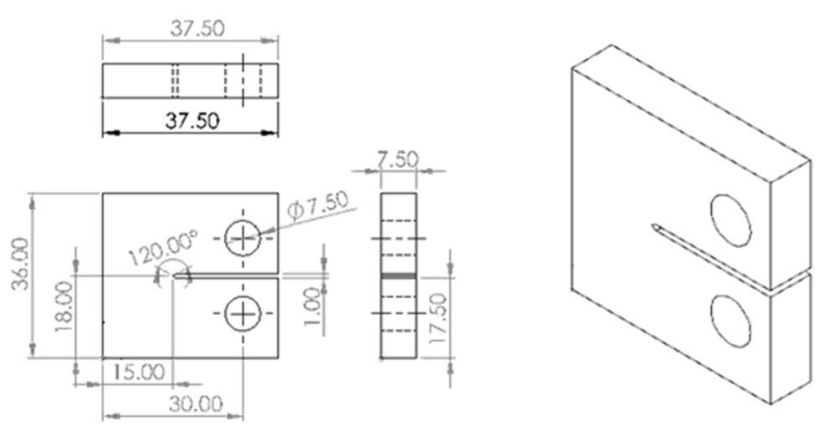

Fig. 1 Schematic diagram of the CT specimen (All units are in $\mathrm{mm}$ ) 

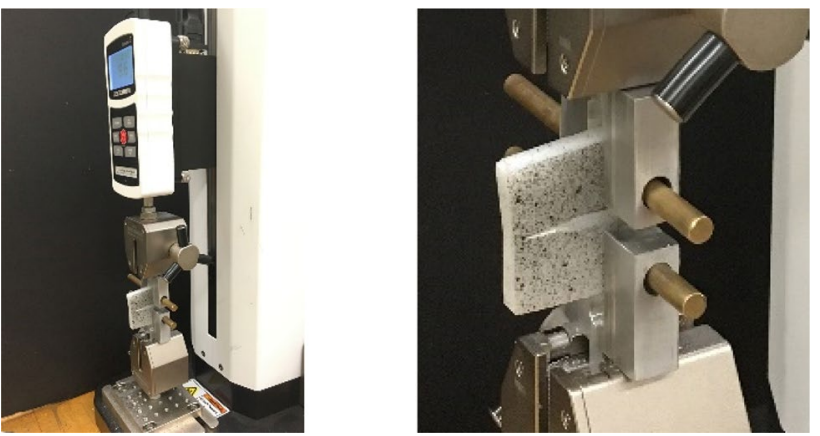

Fig. 2 Experimental setup for compact tension test

energy release rate $\left(G_{I C}\right)$ using the equations described below.

For the $\mathrm{CT}$ specimen, the critical stress intensity factor $\left(\mathrm{K}_{\mathrm{IC}}\right)$ was calculated using the following formula, as per ASTM D5045:

$K_{I C}=\frac{P}{B W^{1 / 2}} \cdot f\left(\frac{a}{W}\right)$

where

$f\left(\frac{a}{w}\right)=\frac{\left(2+\frac{a}{w}\right)\left\{0.886+4.64\left(\frac{a}{w}\right)-13.32\left(\frac{a}{w}\right)^{2}+14.72\left(\frac{a}{w}\right)^{3}-5.6\left(\frac{a}{w}\right)^{4}\right\}}{\left(1-\frac{a}{w}\right)^{3 / 2}}$

\subsection{Characterization of the modified HNT fillers and the nanocomposite}

The pristine and the functionalized HNTs were analyzed by thermogravimetric analysis (TGA, TA Instruments, TGA Q50) under a nitrogen atmosphere from room temperature to $700{ }^{\circ} \mathrm{C}$ by $10^{\circ} \mathrm{C} / \mathrm{min}$ to determine the amount of the siloxy loading and the thermal stability of the HNT. The nitrogen flows for both the balance and sample is $20.0 \mathrm{ml} /$ min. The Fourier-Transform Infrared Radiation Spectromto detect the prominent functional groups and molecular structures of the clay $(\sim 10 \mathrm{mg})$ before and after the functionalization of the organosilane groups. The FTIR was carried out at room temperature with 32 scans. The Powder X-ray Diffraction (PXRD; X-Ray Powder Diffractor (Rigaku, $X$ taLAB Mini) study dealt with the intercalation and the basal spacing of the clay and was performed with a $\mathrm{Cu}$ Ka radiation $(\lambda=0.1541 \mathrm{~nm})$ at $45 \mathrm{kV}$ and $40 \mathrm{~mA}$. Scanning was carried out from $0^{\circ}$ to $70^{\circ}$, at a rate of $0.2^{\circ} \%$. The $d$-spacing of the layered particle was then calculated from Bragg's equation, $n \lambda=2 d \sin \theta$, where $\lambda$ is the wavelength of the X-ray, $d$ is the interlayer distance, and $\theta$ is the angle eter (FTIR; Thermo Scientific ${ }^{\mathrm{TM}}$ Nicolet $^{\mathrm{TM}}$ iS $^{\mathrm{TM}} 10$ ) was used
$P$ is the maximum load in $k N, B$ is the specimen thickness in $\mathrm{cm}, \mathrm{W}$ is the specimen width in $\mathrm{cm}$, and $\mathrm{a}$ is the crack length as determined in $\mathrm{cm}$. For the compact tension specimen, the value of the strain energy release rate $\mathrm{G}_{\mathrm{IC}}$ in units of $\mathrm{kJ} / \mathrm{m}^{2}$ from the corrected energy, $\mathrm{U}$, can be calculated as follows:

$G_{I C}=\frac{U}{B W \varphi}$

where the energy-calibration factor, $\varphi$, shall be computed from of incident X-ray radiation.

The morphological characteristics of nanofillers and nanocomposites were carried out by JEOL JSM-7600F Field Emission Scanning Electron Microscope (FESEM) equipped with Energy Dispersive X-Ray Spectrometer (EDS) and was operated at $30.0 \mathrm{kV}$ with a working distance of $\sim 10 \mathrm{~mm}$. Samples for SEM were pre-coated with palladium/gold sputter coating to improve the conductivity before the test, images were then taken to analyze the nanoclay morphology of each sample and were compared with the resulting as-received (AR)-HNT composite

$$
\begin{aligned}
& \varphi=\frac{\left(1.9118+19.118\left(\frac{a}{w}\right)-2.5122\left(\frac{a}{w}\right)^{2}-23.226\left(\frac{a}{w}\right)^{3}+20.54\left(\frac{a}{w}\right)^{4}\right)\left(1-\left(\frac{a}{w}\right)\right)}{\left(19.118-5.0244\left(\frac{a}{w}\right)-69.678\left(\frac{a}{w}\right)^{2}+82.16\left(\frac{a}{w}\right)^{3}\right)\left(1-\left(\frac{a}{w}\right)\right)} \\
& +2\left(1.9118+19.118\left(\frac{a}{w}\right)-2.5122\left(\frac{a}{w}\right)^{2}-23.226\left(\frac{a}{w}\right)^{3}+20.54\left(\frac{a}{w}\right)^{4}\right)
\end{aligned}
$$

The energy, $U$, is derived from the integration of the load versus displacement curve up to the same load point as used for $K_{I C}$. materials. For the nanocomposites, each sample was cut in ultra-thin sections and placed on the carbon-coated copper grids. Representative specimens were analyzed with 
SEM and EDS to determine the elemental composition and morphology of the fracture surfaces of the materials, respectively.

\section{Results and discussion}

\subsection{Thermogravimetric analysis (TGA)}

The primary analysis carried out on each synthesized compound was through TGA and was to predominantly determine the percent loading of the organosilane onto the surface of the clay and to analyze the thermal integrity of each compound. Figure 3 shows the thermogravimetric analysis results of HNT (a), HNT modified with epoxy (b), and thiol (c). In general, the mass loss profiles show very similar and small mass differences below $200{ }^{\circ} \mathrm{C}(<2.8 \%)$, which was allocated to the residual solvents, moisture, and gases absorbed on the clay. The HNT at $<200{ }^{\circ} \mathrm{C}$ shows the $2.8 \%$ loss of HNT, which is higher when compared to the grafted HNTs (epoxy-1.37\% and thiol-2.07\%); this is due to the utilization of the residual water during the silylation process itself $[32,47,48]$. The mass loss between $200^{\circ} \mathrm{C}$ and $400^{\circ} \mathrm{C}$ is attributed to the decomposition of the organosilane from the surface of the clay, and the gradual loss of the interlayer water. The mass loss beyond $400{ }^{\circ} \mathrm{C}$ is by the dehydroxylation of the aluminol groups of the clay and the remaining covalently bonded organosilane groups $[25,49,50]$. Results showed that HNT loses $1.863 \%$ of its weight within a range of $200-400{ }^{\circ} \mathrm{C}$, but the functionalized HNT lost $10.15 \%$ for epoxy and $3.25 \%$ for thiol in the same temperature range. The major loss is seen in the temperature range from 400 to $700^{\circ} \mathrm{C}$ (Table 1). The formation of an additional peak in the range $200^{\circ} \mathrm{C}$ to $400^{\circ} \mathrm{C}$ for epoxy and thiol group also substantiate for the loss of the organosilane group (Fig. 3b, c).

The data collected from TGA analysis is summarized in Table 1, which shows mass \% losses at different temperature ranges, and calculated mmol siloxy group per gram of clay. Results indicated that the lowest and highest mass \% losses within the highest temperature range, $200-700^{\circ} \mathrm{C}$, are exhibited by pure HNT and HNT functionalized by epoxy, respectively.

The quantitative analysis (molar amount) of the grafted organosilane loading was determined using the adapted Eq. (5) $[51,52]$,

$X=\frac{A-B}{100-(A-B)} \times \frac{1}{M W}$

where: $\mathrm{X}$ is the molar amount of grafted organosilane per gram of clay; $A$ is the mass \% loss of a modified HNT from 200 to $700^{\circ} \mathrm{C}, \mathrm{B}$ is the mass \% loss of a pure HNT clay from
200 to $700^{\circ} \mathrm{C}$; and $\mathrm{MW}$ is the molar mass of the hydrolyzed organosilane. $(A-B)$ is the difference in mass loss of the functionalized HNT and the pure HNT. For this calculation, the mass $\%$ loss from 200 to $700{ }^{\circ} \mathrm{C}$ is taken into consideration since all the organosilane is completely decomposed in this range. The molar mass of hydrolyzed GLYMO is $194.34 \mathrm{~g} / \mathrm{mol}$ and for MEPES $154.42 \mathrm{~g} / \mathrm{mol}$. The mass loss for the functionalized HNT is larger than the mass loss in the unmodified clay because of the decomposition of the organosilane group. The results show the molar amount of silane per gram of HNT is higher in epoxy than that of thiol.

\subsection{Field emission scanning electron microscopy (FESEM)}

FESEM observations were performed to study the morphology of pristine and modified HNTs (Fig. 4). The SEM images show the tubular shape of the pure HNT was retained ever after the functionalization of the material [53]. The average characteristic size of HNT (external diameter of 30-100 nm, an inner diameter of 6-30 nm, and $60-480 \mathrm{~nm}$ in length) [54-56] was preserved in both functionalized materials $[45,57]$. The epoxy modified HNT was found in the form of aggregates with some globules on the surface of the tubes. The thiol modified HNT also retained its characteristic tubular feature. For pure HNT tubes, the outer diameter was found to be $46.06 \mathrm{~nm}$ (Fig. 4a). On the other hand, the HNT-epoxy (Fig. 4b) and HNT-thiol (Fig. 4c) exhibited approximately $95.4 \mathrm{~nm}$ and $78.6 \mathrm{~nm}$ in outer diameters, respectively, showcasing the loading of the organosilane group on the tubes. The inner diameters of pure HNT, HNT-epoxy, and HNT-thiol were $26.09 \mathrm{~nm}, 13.6 \mathrm{~nm}$, and $18.85 \mathrm{~nm}$ respectively. The increase in the outer diameter and the decrease in the inner lumen both support the grafting of the organosilane groups on the clay $[45,57]$.

\subsection{Energy dispersive X-ray analysis (EDS)}

The SEM-EDS elemental mapping of surface-modified HNT with epoxy and thiol is shown in Fig. $5 a$, b respectively. The major constituents of HNT are oxygen, aluminum, and silicon. The HNT-epoxy shows the presence of carbon along with the oxygen, silicon, and aluminum [57]. The HNT-thiol illustrates the existence of sulfur confirming the loading of thiol group through covalently bonded organosilane [45, 58]. Small peaks of calcium, chloride, palladium, and gold are present because of the calcium salts (calcium carbonate or chloride) from the clay, and pre-coating with palladium/gold on the material [59]. The sulfur \% though TGA analysis and EDS experiments are found to be consistent ( 0.1\%). 
Fig. 3 Thermogravimetric analysis results: (a) HNT, (b) HNT-epoxy, and (c) HNT-thiol
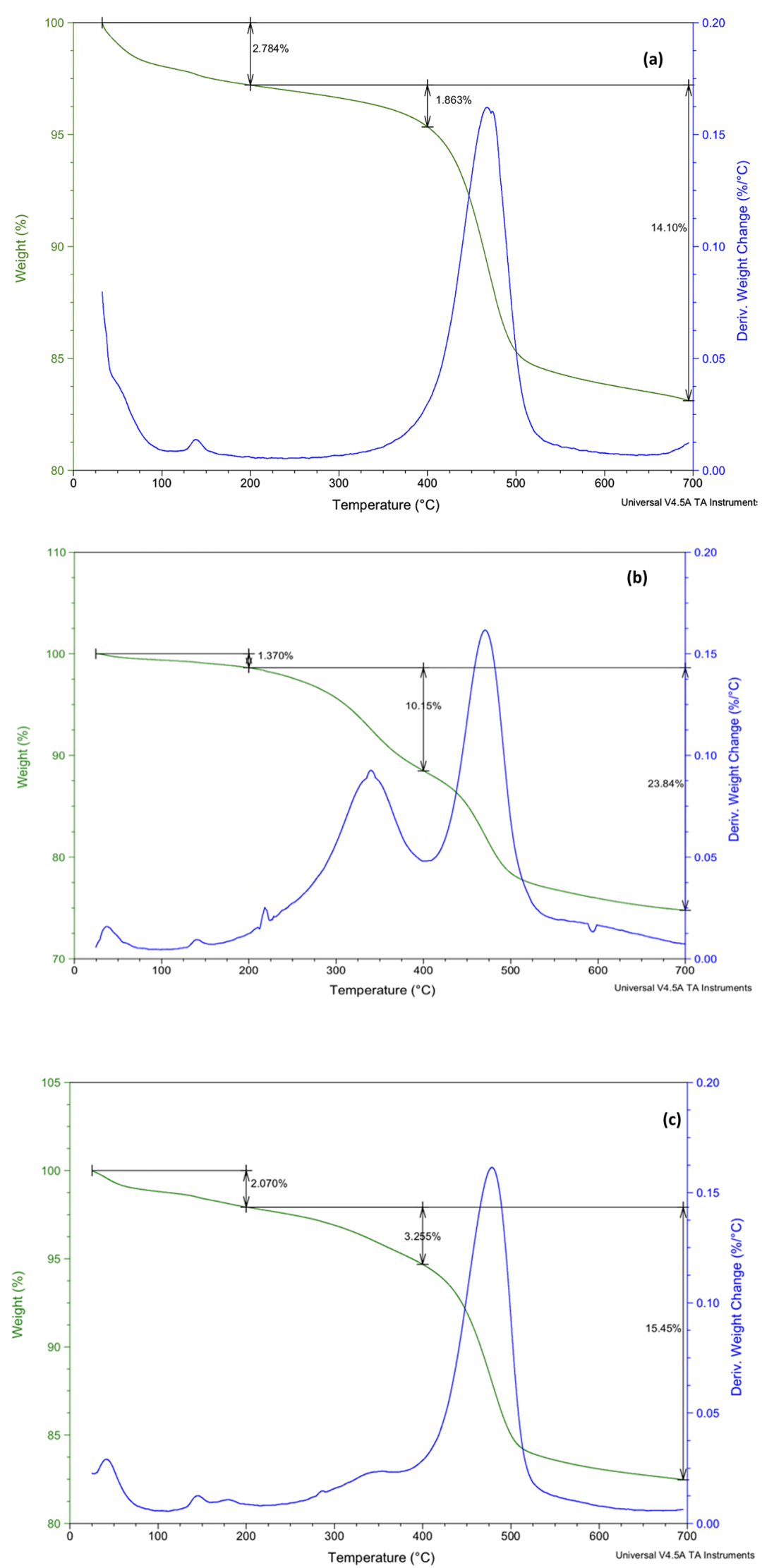
Table 1 Mass \% loss of pure and modified clays, including the amount of silane reacted (mmol of silane per gram) with HNT surface with epoxy and thiol modifiers

\begin{tabular}{lllllll}
\hline Clay & RT-200 ${ }^{\circ} \mathrm{C}$ & $200-400{ }^{\circ} \mathrm{C}$ & $400-700^{\circ} \mathrm{C}$ & $200-700{ }^{\circ} \mathrm{C}$ & $\begin{array}{l}\text { mmol of } \\
\text { silane/g of } \\
\text { HNT }\end{array}$ & DTG temperature peaks \\
\hline HNT & 2.784 & 1.863 & 12.23 & 14.10 & 0.0 & $473^{\circ} \mathrm{C}$ \\
HNT-epoxy & 1.370 & 10.15 & 13.69 & 23.84 & 0.5552 & $339^{\circ} \mathrm{C}$ and $473^{\circ} \mathrm{C}$ \\
HNT-thiol & 2.070 & 3.255 & 12.19 & 15.45 & 0.0886 & $3477^{\circ} \mathrm{C}$ and $478{ }^{\circ} \mathrm{C}$
\end{tabular}

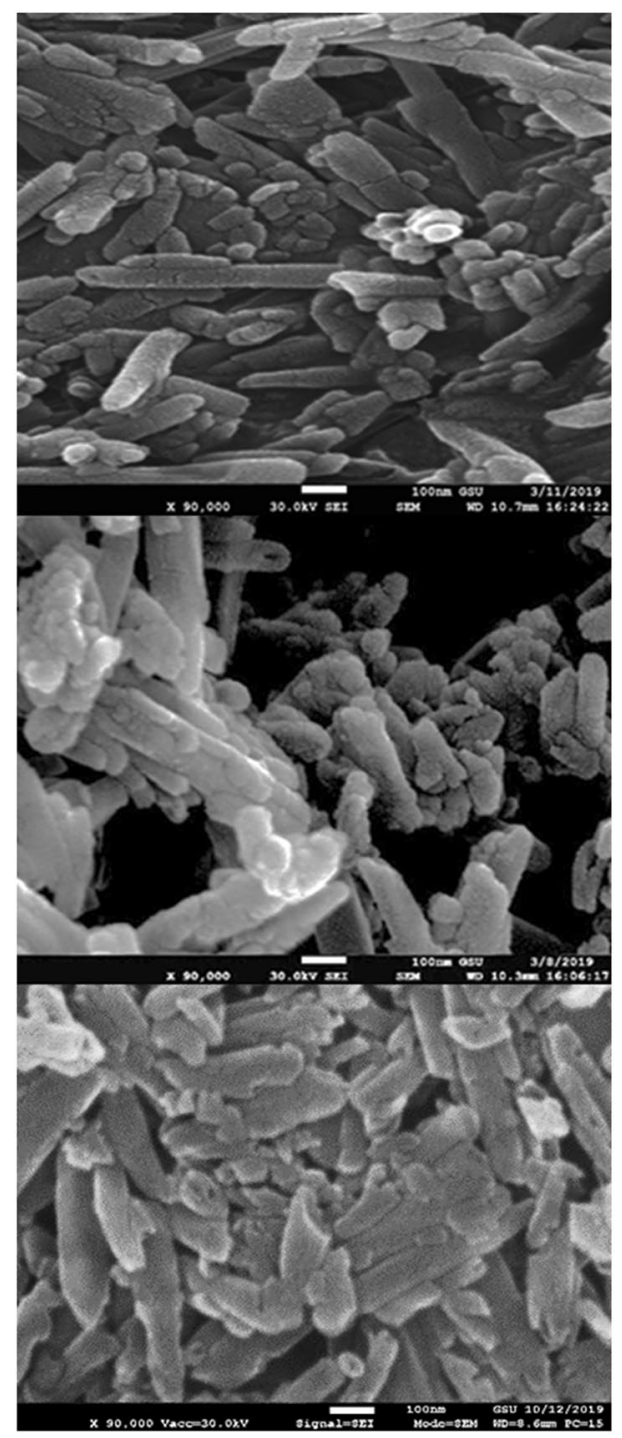

a) Pristine HNT

b) HNT-epoxy

c) HNT-thiol

Fig. 4 SEM images: (a) pristine HNT; (b) HNT-epoxy; and (c) HNTthiol with X90000 magnification

\subsection{Fourier-transform infrared spectroscopy}

Further characterization of clays was carried out through FTIR to understand the molecular structure. As shown in Fig. 6, in each spectrum, the distinct $3690 \mathrm{~cm}^{-1}$ and $3620 \mathrm{~cm}^{-1}$ bands are very typical for the HNTs from two $\mathrm{Al}-\mathrm{OH}$ inner surface stretching bands [57]. Intense peaks can be seen at $911 \mathrm{~cm}^{-1}$ contributing towards single $\mathrm{Al}-\mathrm{OH}$ bending frequencies and $1090 \mathrm{~cm}^{-1}$ for the stretching mode of apical $\mathrm{Si}-\mathrm{O}$ bond. The strongest band of $1029 \mathrm{~cm}^{-1}$ and $1080 \mathrm{~cm}^{-1}$ is resulted by the stretching vibrations of in-plane $\mathrm{Si}-\mathrm{O}-\mathrm{Si}$. The $534 \mathrm{~cm}^{-1}$ band is a characteristic peak for the deformation vibration of $\mathrm{Al}-\mathrm{O}-\mathrm{Si}$ group for HNTs [60].

Compared with the pristine HNTs, the epoxy modified HNTs showed new weak bands at $2935 \mathrm{~cm}^{-1}$ and $2670 \mathrm{~cm}^{-1}$, as shown in section A-A of Fig. 6 . Similarly, HNT-thiol showed peaks at $2885 \mathrm{~cm}^{-1}, 2960 \mathrm{~cm}^{-1}$ and $2985 \mathrm{~cm}^{-1}$ all corresponding to the asymmetric and symmetric stretching vibration of aliphatic $-\mathrm{CH}_{2}-$ groups.

The presence of some interlayer water is suggested by the observation of the $-\mathrm{OH}$ stretching and bending vibrations at $3553 \mathrm{~cm}^{-1}$ and $1640 \mathrm{~cm}^{-1}$ for both thiol and epoxy groups, respectively. The epoxy group is generally seen at $1050-950 \mathrm{~cm}^{-1}$ but due to the huge overlap from the $1029 \mathrm{~cm}^{-1}$ peaks, the single $\mathrm{C}-\mathrm{O}$ weak band is not visible. The band due to the $\mathrm{S}-\mathrm{H}$ stretching vibration $\left(2600-2540 \mathrm{~cm}^{-1}\right)$ has usually low intensity [32]. The results confirm the loading of the organosilane groups as well as the retention of the molecular structure of HNTs.

\subsection{Powder X-ray diffractometer (PXRD)}

The PXRD experiments were carried out with a $\mathrm{Cu}$ tube operation, at $45 \mathrm{kV}$ and $40 \mathrm{~mA}$. Scanning was done from $0^{\circ}$ to $70^{\circ}$, at a rate of $0.2^{\circ} / \mathrm{s}$ [25]. The data was collected for all the three clays and used to calculate and compare the primary interspacing distances for each compound. The first order basal reflection (001) for the pure HNT is seen at $7.43 \AA$, which is very close to the previously reported data (Table 2) $[25,61,62]$. Epoxy, and thiol modified HNTs produced spacing of $7.26 \AA$ and $7.29 \AA$ [63], respectively. For the pure HNT, the $2 \theta$ positions of $19.98^{\circ}$ and $24.92^{\circ}$ confirm the dehydrated state of HNT with (020) and (002) basal reflection, shown in Fig. 7. The (020) peak position trend is what is anticipated from each species, due to the addition of the organosilane decreasing the spacing of each molecule. The basal reflection peak at (001) is reported for functionalized HNTs suggesting that no intercalation of organosilane occurred in the lumen of HNT [45]; it is 


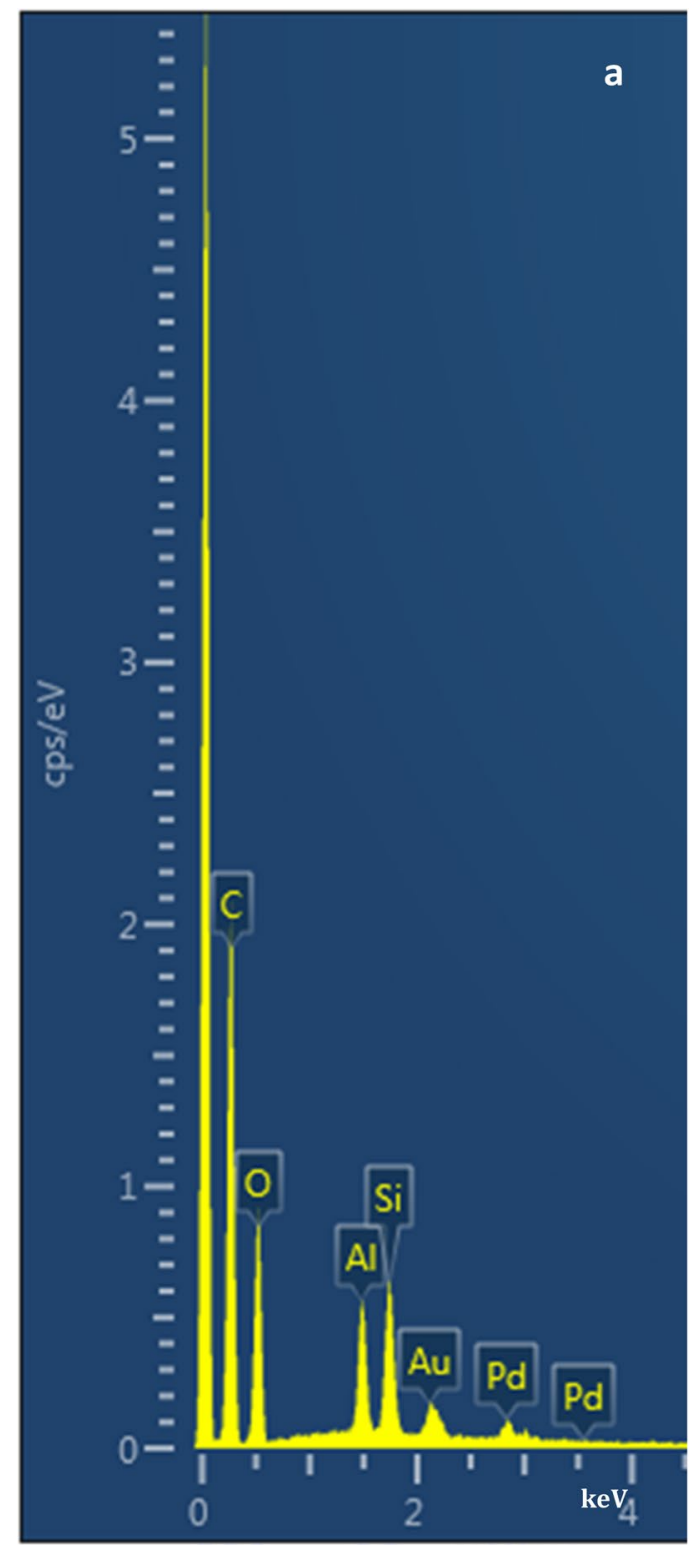

Fig. 5 EDS spectra of (a) HNT-epoxy; and (b) HNT-thiol

also such a small sizing difference that it can be attributed to such a low amount of loading for each modified clay that the spacing and orientation of the nanotubes is not adjusted greatly [64]. The PXRD data provides evidence that the original structure of the HNT was maintained even after surface grafting with epoxy and thiol groups.

\subsection{Fracture toughness test}

Figure 8a shows the experimental setup of the compact tension (CT) testing and Fig. $8 \mathrm{~b}-\mathrm{d}$ shows the load-displacement curves obtained from $\mathrm{CT}$ test at room temperature for each material configuration: pure SC-15, HNT, HNT-epoxy, and HNT-thiol nano-modified composites.

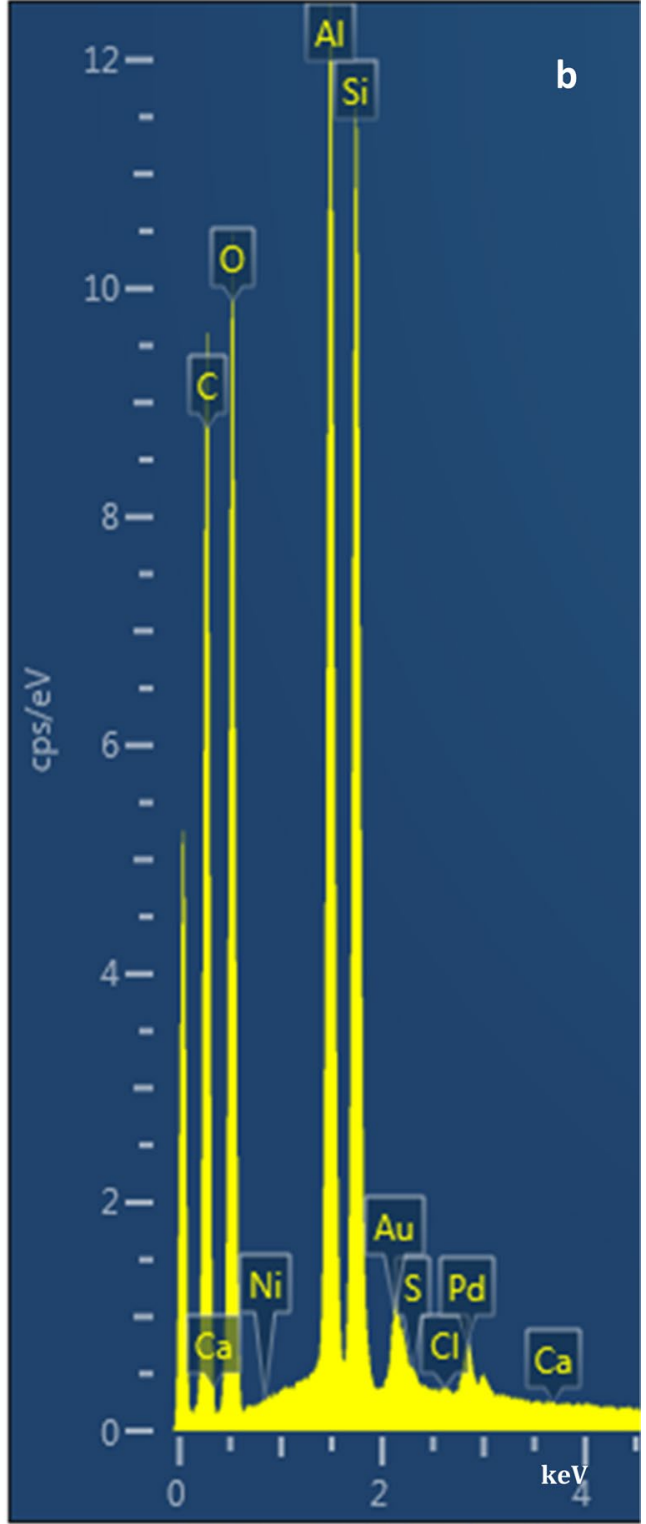

The data showcase the inclusion of nano-fillers improved the load-carrying capacity and crack opening displacement in the mode-I test. Except at 2\% HNT (Fig. 8b), 1\% HNT-epoxy (Fig. 8c), and 2\% HNT-thiol (Fig. 8d) modified SC-15 epoxy, all specimens showed unstable crack propagation under a continuous loading condition followed by a drastic load drop to zero after reaching the peak load. The load drops implied the existence of a linear elastic and brittle behavior in the materials. As shown in the figure, the improved loading carrying capacity observed in the $2 \%$ HNT and $2 \%$ HNT-thiol modified composites can be due to the presence of better interfacial bonding between the nanofillers and the host SC-15 epoxy. Inclusion of a higher concentration of 


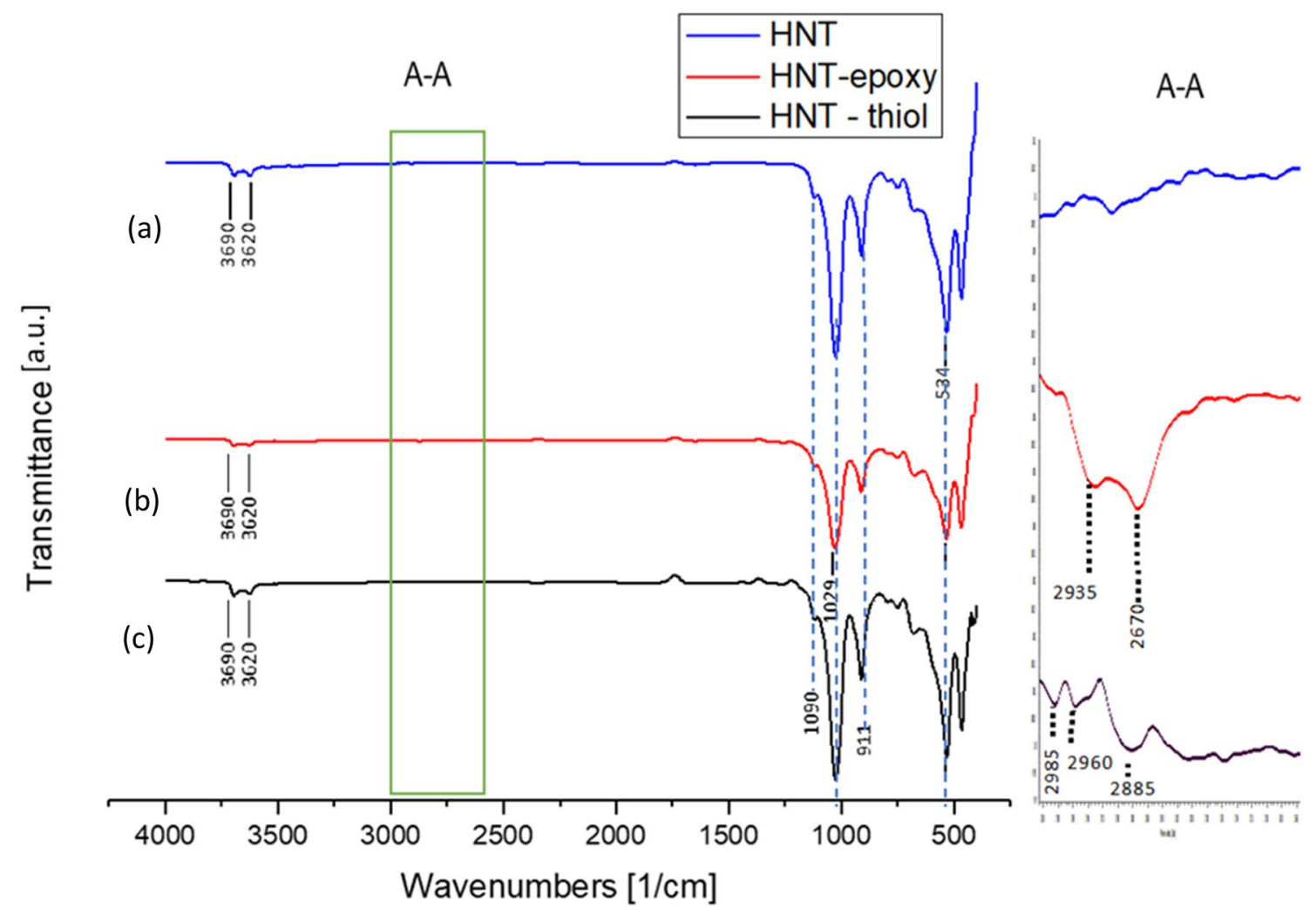

Fig. 6 FTIR images of pure (a; blue) and modified clay; epoxy (b; red) and thiol (c; gray). The expanded portion from $2600 \mathrm{~cm}^{-1}$ to $3000 \mathrm{~cm}^{-1}$ is shown in the inset

Table 2 The parameters of the peaks identified in the pure and modified HNT materials

\begin{tabular}{llll}
\hline Material & Basal reflection & Position $(2 \theta)$ & $d$-spacing $(\AA)$ \\
\hline Pure HNT & 001 & 11.898 & 7.430 \\
& 020 & 19.986 & 4.437 \\
& 002 & 24.924 & 3.568 \\
HNT-epoxy & 001 & 12.173 & 7.262 \\
& 020 & 20.128 & 4.406 \\
& 002 & 24.757 & 3.592 \\
HNT-thiol & 001 & 12.123 & 7.291 \\
& 020 & 20.061 & 4.420 \\
& 002 & 24.681 & 3.602 \\
\hline
\end{tabular}

halloysite nanofillers within the matrix helped to arrest/ delay multiple cracks caused by plastic deformation in the specimen from being propagated rapidly, and as a result, allowed the continuing load rise and fall prior catastrophic failures, as can also be seen in Fig. 9. In the case of HNT-epoxy (Fig. 8c), the maximum load-displacement occurred at $1 \%$ weight content, unlike the HNT and HNTthiol nanocomposites that showed the highest value at $2 \%$. However, the value was reduced by about $17 \%$ and

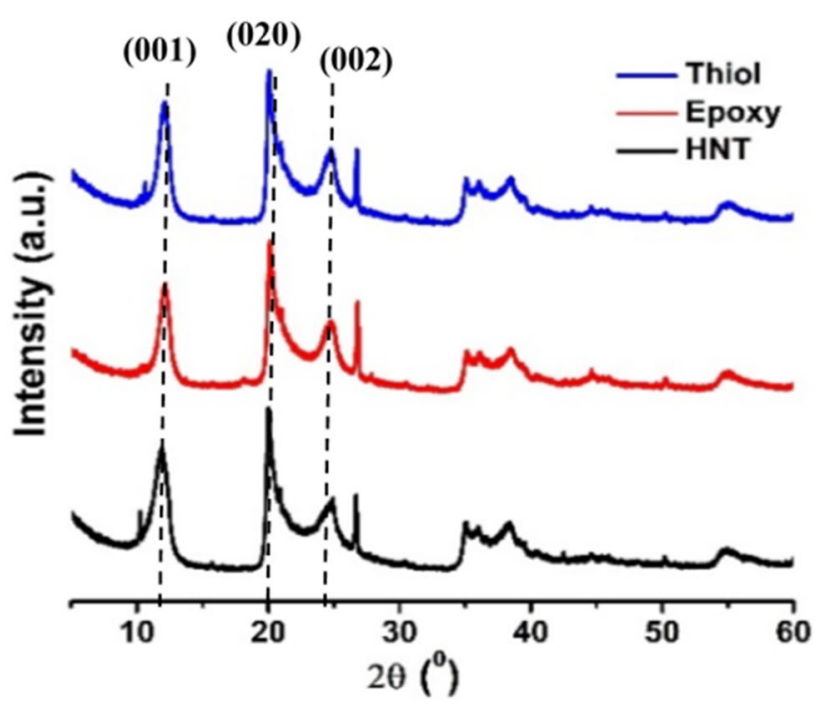

Fig. 7 XRD patterns of pristine HNT (black), HNT with epoxy (red), and HNT with thiol (blue) groups

$29 \%$ as compared with HNT and HNT-thiol nanocomposites, respectively. The reason for having a reduced loadcarrying capacity enhancement at relatively medium 


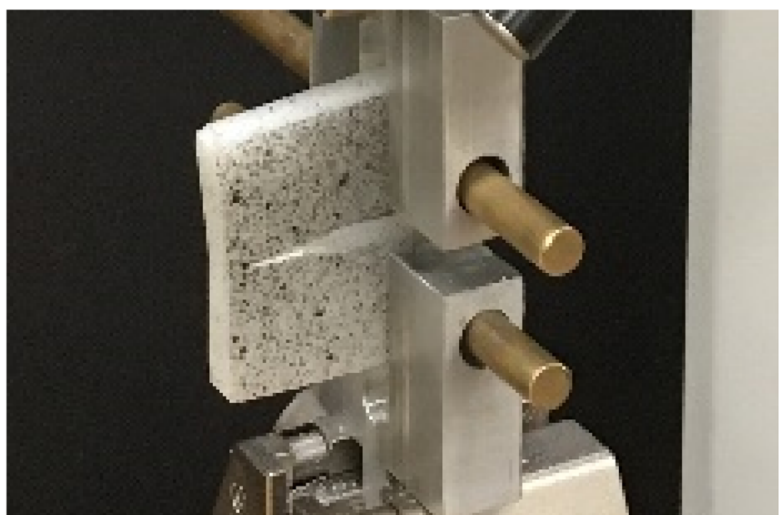

(a)

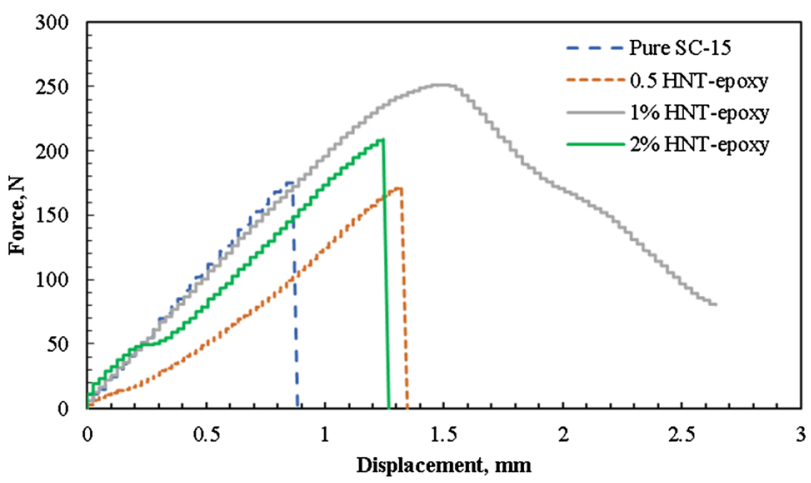

(c)

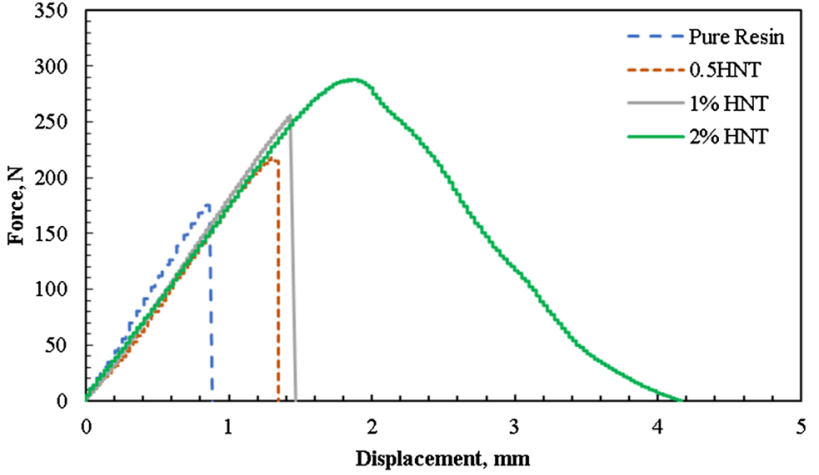

(b)

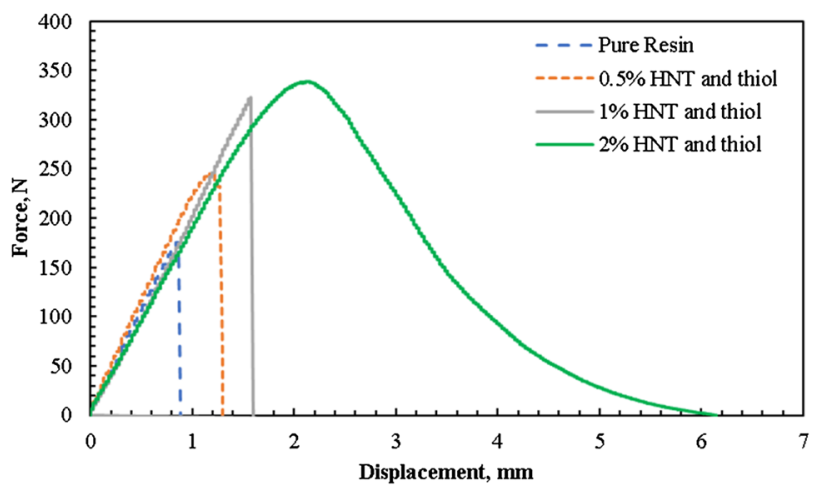

(d)

Fig. 8 Comparison of load-displacement curves of pure SC-15 resin and synthesized nanocomposites at different concentrations: (a) CT experimental setup, (b) HNT, (c) HNT-epoxy, (d) HNT-thiol

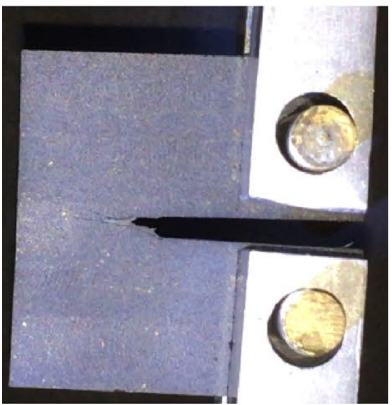

Pure SC-15 Resin

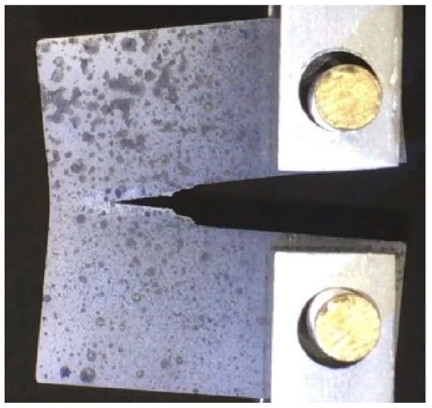

2\% HNT pure

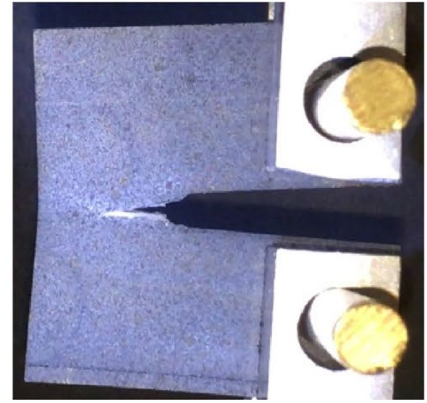

1\% HNT-epoxy

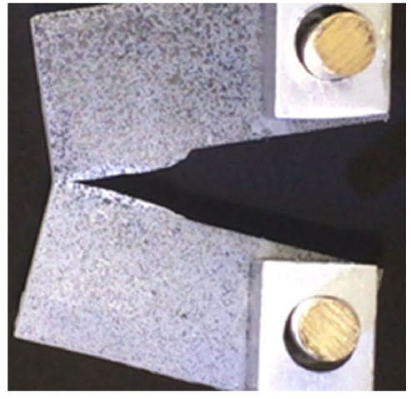

2\% HNT-thiol

Fig. 9 Comparison of crack openings of pure SC-15 resin and nanocomposites prior to total fracture

concertation could be attributed to the brittle nature of coated epoxy applied on the halloysite surface that reduced the plastic deformation of the nanocomposite and load-carrying capacity: the crack opening displacement of 1\% HNT-epoxy (Fig. 8c) significantly reduced as compared to the other nanocomposites.
Figure 10a, $b$ show the comparison of the critical fracture toughness $\left(K_{I C}\right)$ and strain energy release rates $\left(G_{I C}\right)$ of pure SC-15 and nanocomposites, respectively. Generally, the addition of pure and functionalized HNT nanofillers in SC-15 changed the $\mathrm{K}_{\mathrm{IC}}$ and $\mathrm{G}_{\mathrm{IC}}$. The inclusion of $2 \%$ of HNT improved $K_{I C}$ by $71 \%$. Similarly, functionalized 


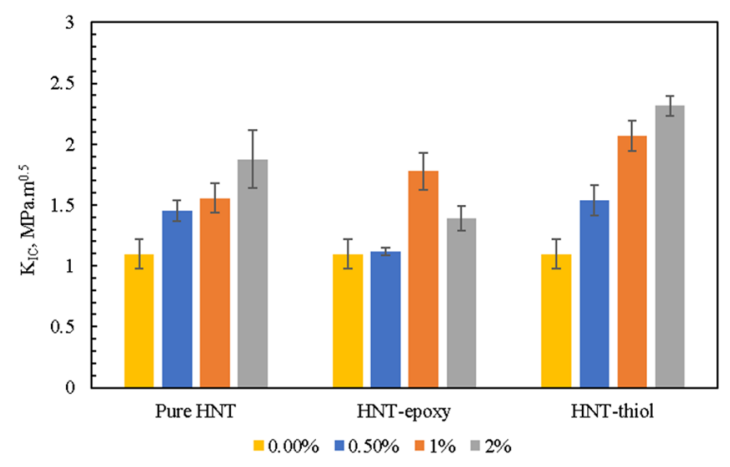

(a)

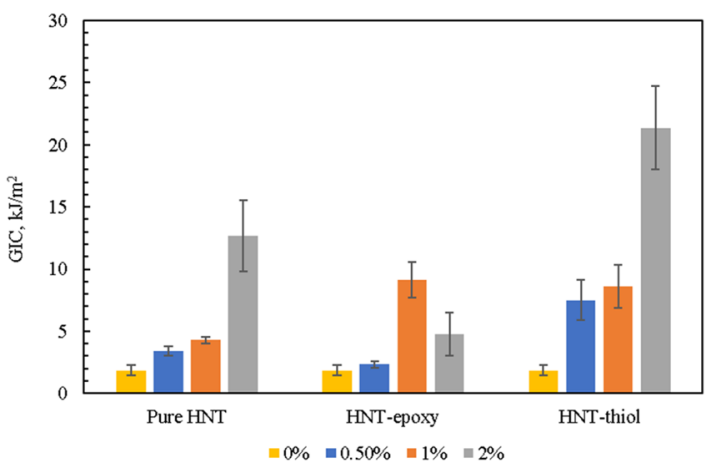

(b)

Fig. 10 Effect of various functionalized halloysite fillers on: (a) critical fracture toughness $\left(\mathrm{K}_{\mathrm{IC}}\right)$; $(\mathbf{b})$ on critical strain energy release rate $\left(\mathrm{G}_{\mathrm{IC}}\right)$

$2 \%$ HNT-thiol exhibited the highest $\mathrm{K}_{\mathrm{IC}}$ enhancement, by $111 \%$, compared to the remaining nanocomposites. The $1 \%$ weight concentration of HNT-epoxy nanocomposite showed better $\mathrm{K}_{\mathrm{IC}}$ performance, $67 \%$ enhancement, as compared with the $0.5 \%$ and $2 \%$ HNT-epoxy specimens.

Similarly, the $\mathrm{G}_{\mathrm{IC}}$ is improved as the nanofiller contents increased. As observed in Fig. 10b, the 2\% HNT, 1\% HNTepoxy, and $2 \%$ HNT-thiol modified composites exhibited the highest $\mathrm{G}_{\mathrm{IC}}$ within their respective categories by $276 \%$, $182 \%$, and $413 \%$. These improved fracture toughness and strain energy released rates were achieved due to the presence of well-dispersed halloysite nanofillers and multipleenergy absorbing mechanisms in the SC-15 epoxy. The presence of halloysite nanofillers caused the initiation of plastic shear of deformation bands, pseudo ductile deformation, blunted the crack tip, and consequently slowed down the crack growth [65]. However, for the higher content of functionalized HNT-epoxy to SC-15, there was a significant reduction in the resistance to material fracture. This can be explained by the brittle nature of the coated epoxy interface presented between the outer surface of the halloysite nanotubes, the SC-15 matrix, and clusters in the matrix that minimized the plastic deformation zone. The brittle nature of the coated epoxy on the halloysite nanofillers introduced sudden abrupt crack propagation with a reduced plastic deformation that detrimentally affected the fracture toughness and the strain energy release rate. As the TGA analysis revealed, the presence of a relatively higher amount of epoxy on the surface of HNT nanotubes could undermine the effectiveness of HNT nanotubes to enhance the fracture toughness of the resin. Generally, it is believed that the synergy between the commercially available toughened SC-15 and HNT nanofiller is the most promising and one of the few best results available in the open literature, this would allow us to open up a new alternative avenue for improving the fracture toughness for brittle thermoset materials.

\subsection{Morphology of fracture surfaces}

As reported by the manufacturer, SC-15 is a commercially available toughened epoxy used for several Army composite applications [66]. It is a two-phase toughened epoxy cured with a cycloaliphatic amine. At high magnification (X3000), Figs. 11, 12, 13, 14, 15 show the extent and phaseseparated domains in pristine and nano modified SC-15 epoxies. The introduction of toughening particles, mostly elastomers, facilitated the two-distinct phase morphology that can be detected by scanning electron microscopy as cavitation. As also indicated by Wang et al. [66],

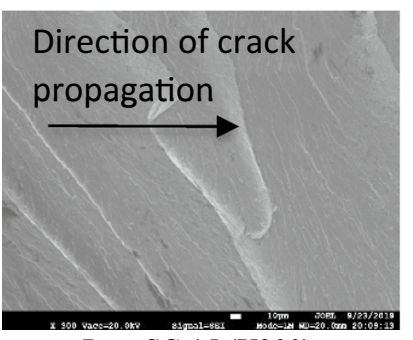

Pure SC-15 (X300)

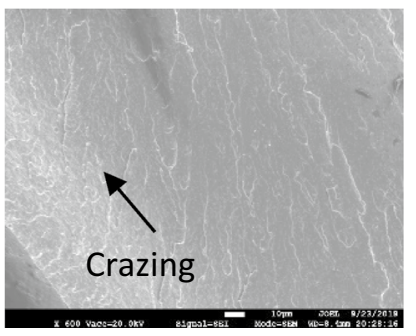

Pure SC15 (X600)

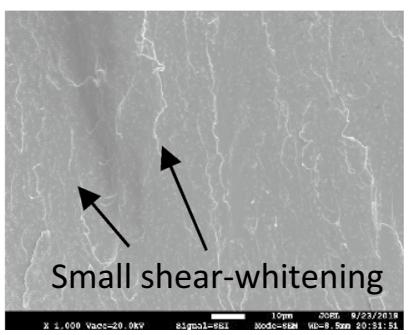

Pure SC15 (X1000)

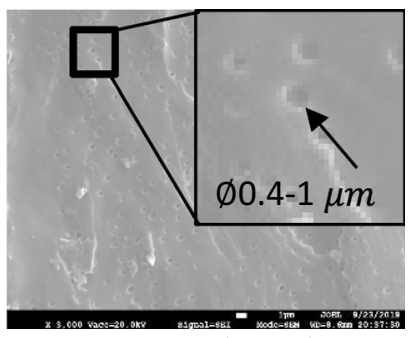

Pure SC15 (X3000)

Fig. 11 SEM observation of pristine SC-15 at increasing magnification from X300-X3000 
$\mathrm{X} 300$
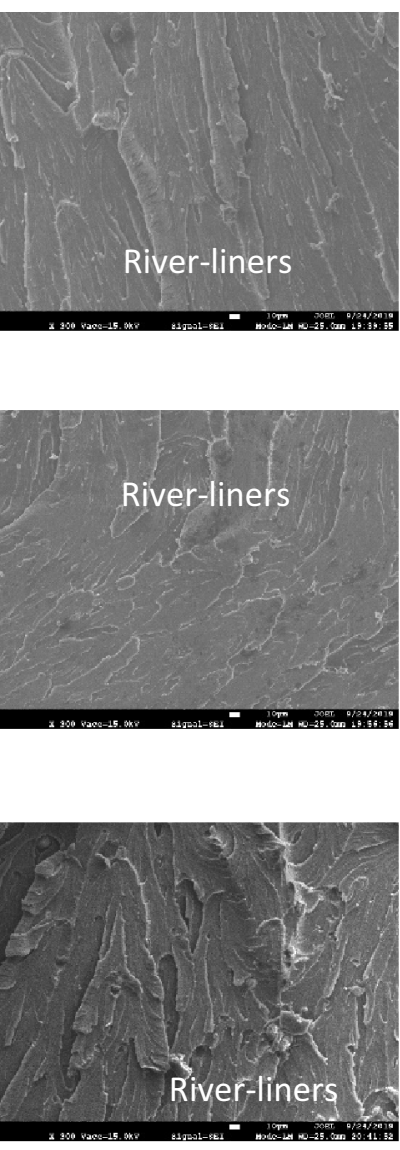

X600

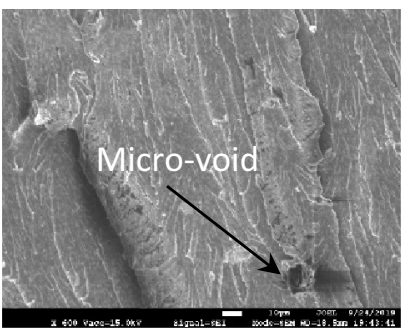

(a) $0.5 \%$ HNT modified SC-15 resin.
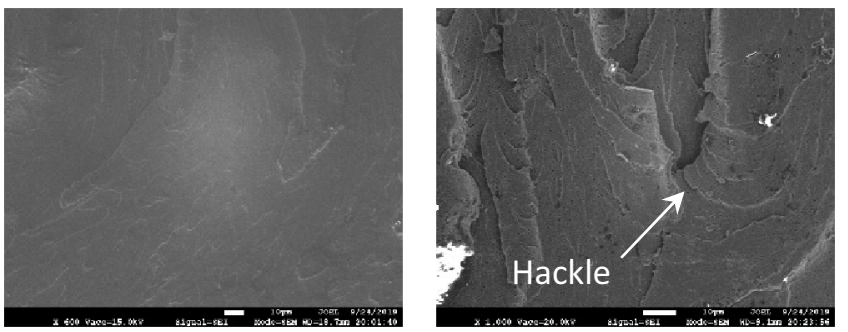

(b) $1 \%$ HNT modified SC-15 resin.
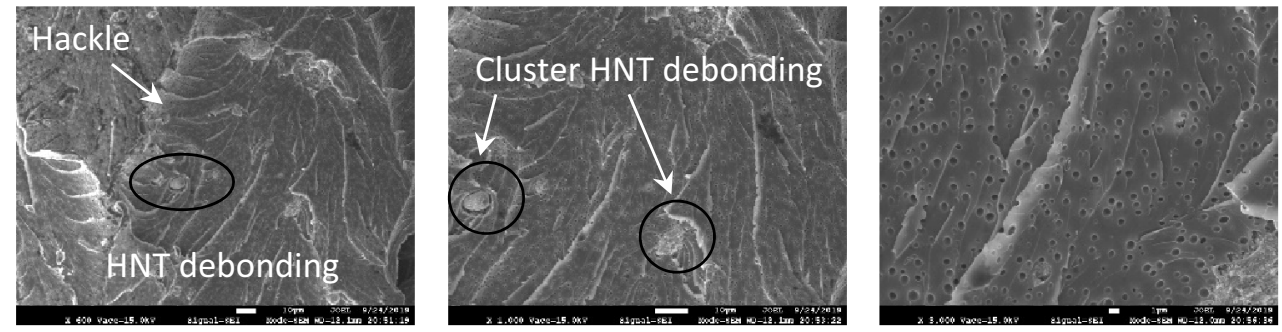

(c) $2 \%$ HNT modified SC-15 resin.

Fig. 12 SEM observation of HNT modified SC-15 at increasing filler loading and magnification from X300-X3000. (a) $0.5 \%$ HNT modified SC-15 resin. (b) $1 \%$ HNT modified SC -15 resin. (c) $2 \%$ HNT modified SC-15 resin

the toughening phase appeared to be around $\varnothing 0.4-1 \mu \mathrm{m}$ in size, as shown in Fig. 11 (Pure SC15 (X3000)).

The morphology and failure mechanisms of mode-I fracture surfaces of nanocomposites filled by pure and functionalized halloysites were examined by SEM. Previous studies $[8,13,62,67-70]$ showed that enhancement in both fracture energy and fracture toughness exhibited by nano-modified composites are strongly related to a large amount of energy dissipated by the presence of various plastic deformation and damage mechanisms taking place at the micro- and nanoscale level.

Figure 11 shows the SEM images of the fractured surfaces of pure SC-15 matrix tested under CT tests at increasing magnification (X300, X600, X1000, and X3000). As noted in the figure, the fractured surfaces were relatively smooth with the presence of some crazing lines at $45^{\circ}$ against the crack propagation, after the crack initiated from its origin. The presence of smooth surfaces indicated that crack propagation occurred drastically, which implied the low pseudo-ductility nature of the material compared to the inclusion of the pure and functionalized HNT modified nanocomposites.

Figures 12, 13, 14, 15 show SEM images of that pure and functionalized HNTs modified SC-15 resins at different loading \% of HNT fillers. The presence of HNT fillers in the matrix evidently changed the toughness mechanics from smooth and low pseudo-ductile (relative term) to several energy absorption mechanisms such as fibrils, crack bridging, crazing, microvoids, and hackles. For example, in HNT modified nanocomposite, the higher pseudo-ductile strain (plastic deformation) was observed, as shown in Fig. 12. One of the toughening mechanisms in the configuration of this material was the crack deflection mechanism [71]. In this mechanism, the nanofillers caused the deviation of crack front to a slightly different plane, which created river lines, shear yielding, hackles, and feathers (Fig. 12a-c). The river liners were generated on the new cleavage plane and at slightly different planes. As the crack propagated, these levels combined to form a crack advancing on fewer parallel planes [72].

\section{SN Applied Sciences


$\mathrm{X} 300$
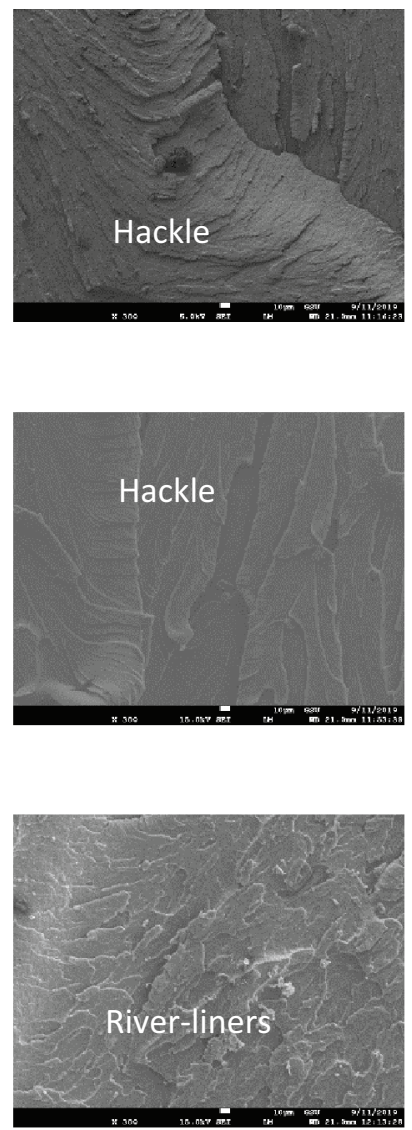

X600

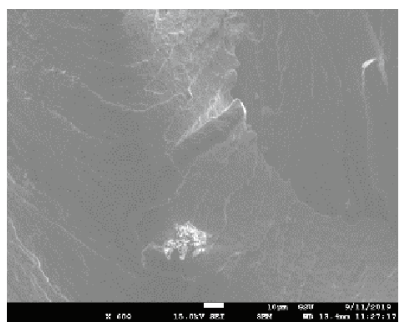

(a) $0.5 \%$ HNT-epoxy modified SC-15 resin.
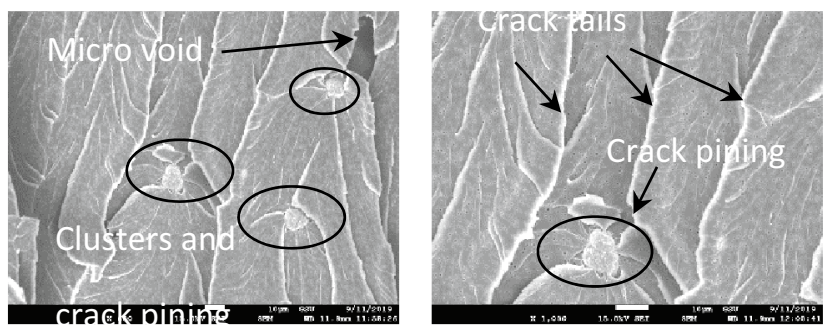

(b) $1 \%$ HNT-epoxy modified SC-15.
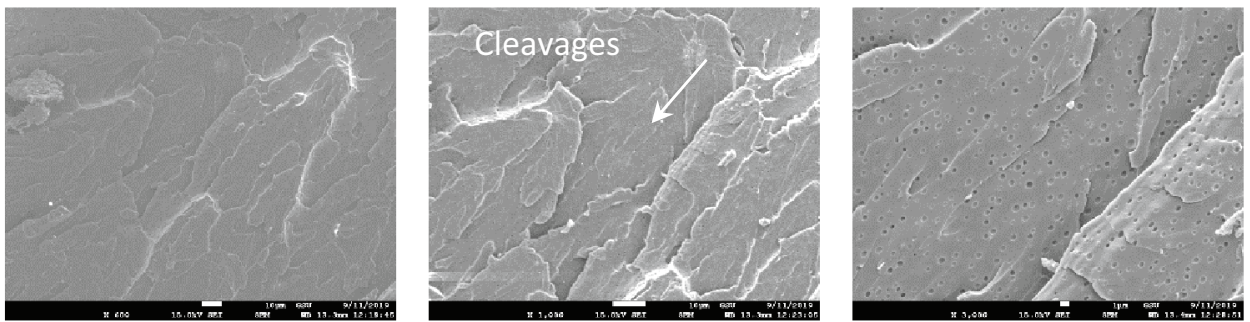

(c) $2 \%$ HNT-epoxy modified SC-15.

Fig. 13 SEM observation of functionalized HNT-epoxy modified SC-15 at increasing filler loading and magnification from X300-X3000. (a) 0.5\% HNT-epoxy modified SC-15 resin. (b) 1\% HNT-epoxy modified SC-15. (c) 2\% HNT-epoxy modified SC-15

The size of hackles and feathers tend to increase as the filler content of HNT increased to $2 \%$, which implied high pseudo-ductile strain that improved the fracture toughness and strain release energy rate of the nanocomposite. (see Fig. 10a, b). Besides, as seen in Fig. 12b, c, the presence of the hackle region indicated the presence of the shear yielding and crack-front branching mechanisms in the HNT nanocomposite [68]. The shear yielding mechanics could also occur by the stress concertation around the periphery of the cluster (agglomerated) halloysites [13]. When compared with other types of functionalized HNT nanocomposites, the HNT nanocomposite exhibited cluster debonding. This result implied that the functionalization of HNT nanofillers improved the interfacial bond between the outer surface of HNTs and the matrix.

Among pure and functionalized HNT nanocomposites, the lowest $\mathrm{K}_{\mathrm{IC}}$ and $\mathrm{G}_{\mathrm{IC}}$ rates were observed in the HNTepoxy nanocomposite (see Fig. 10a, b). These findings can be evidently correlated with the SEM results shown in Fig. 13. As shown in the figure, the presence of coated epoxy on the surface of HNT exhibited a predominance of the crack deflection mechanism, with a lower amount of energy absorbed through the zone shielding mechanism, crack pinning mechanism (Fig. 13b), and low plastic deformation. For example, Fig. 13 shows the zone shielding mechanism represented by the formation of microvoids around the multiple crack tips. Similarly, the crack pining mechanism was observed in the matrix due to the presence of clustered (agglomerated) HNT-epoxy nanofillers. Figure $13 \mathrm{c}$ shows that as the concentration of functionalized HNT-epoxy increased to $2 \%$, the brittle nature of epoxy situated between the halloysite tube and the toughened SC-15 matrix detrimentally affected the energy absorbing mechanism; formation and size of crack tails or the amount of plastic deformation significantly reduced, supporting the reduction of the fracture toughness value, when compared with the $1 \%$ HNT-epoxy nanocomposite, and is also seen in Fig. 10.

The SEM observation of functionalized HNT-thiol revealed the formation of multiple fibrils and deep tail 
$\mathrm{X} 300$
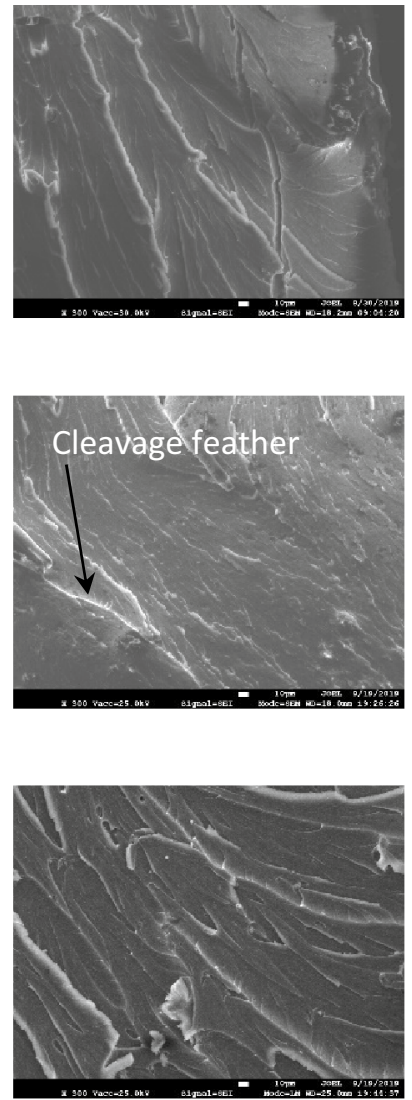

X600

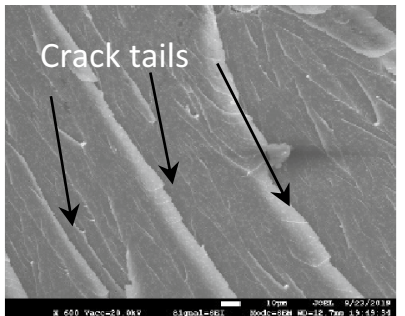

(a) $0.5 \%$ HNT-thiol modified SC-15.

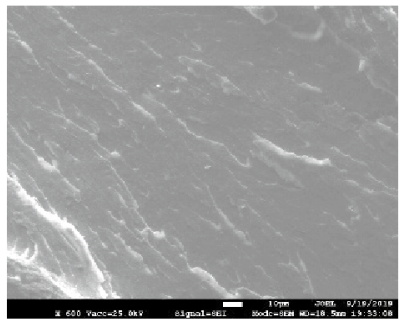

(b) $1 \%$ HNT-thiol modified SC-15.
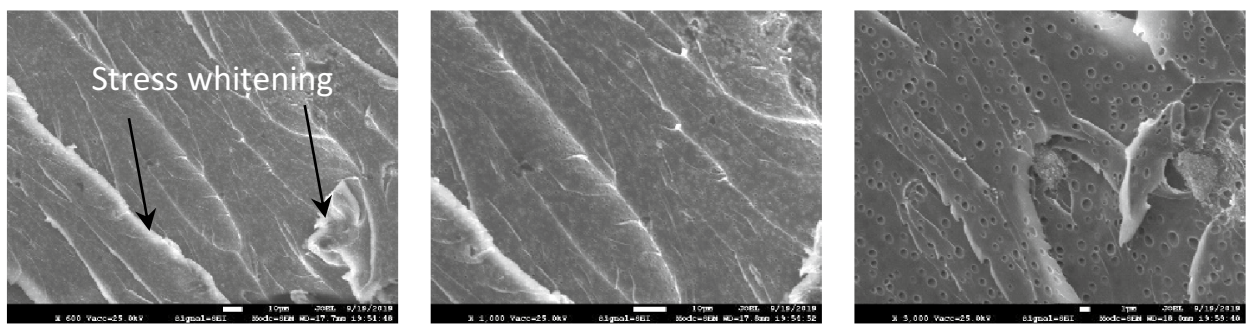

(c) $2 \%$ HNT-thiol modified SC-15

Fig. 14 SEM observation of functionalized HNT-thiol modified SC-15 at increasing filler loading and magnification from X300-X3000. (a) 0.5\% HNT-thiol modified SC-15. (b) $1 \%$ HNT-thiol modified SC-15. (c) 2\% HNT-thiol modified SC-15

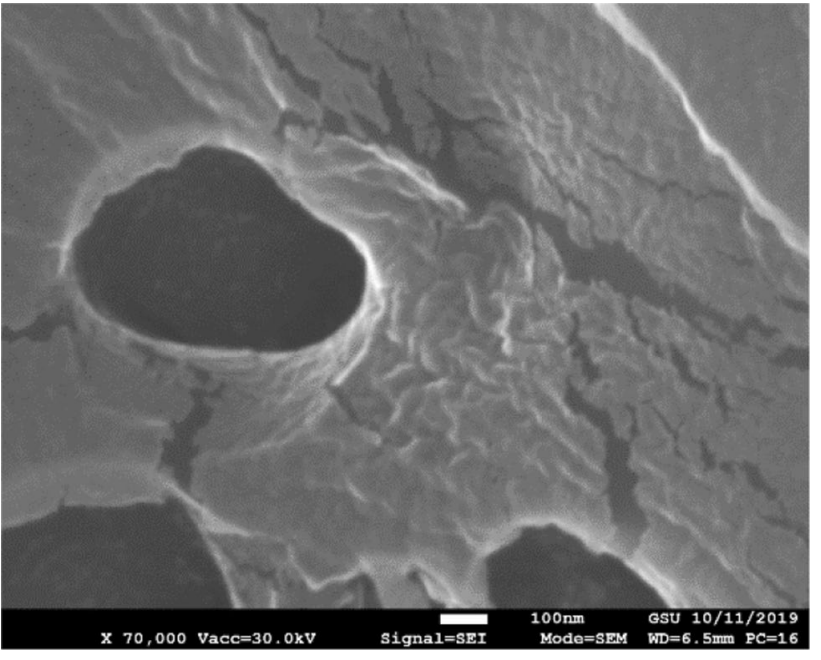

Fig. 15 The stress whitening in HNT-thiol nanocomposite resulted from multiple crack opening, and voids fracture mechanisms within the matrix, as shown in Fig. 14. The high concentration of functionalized HNT-thiol toughening agent increased the occurrence of high plastic deformation, which resulted from crack bridging with the formation of polymer fibrils known to be associated with multiple localized deformations. The highest plastic deformation of the HNT-thiol modified SC-15 was also confirmed by a visual observation shown in Fig. 9. Generally, the fibrils formation mechanism could be associated with: (i) void generation by debonding between the functionalized HNT-thiol and SC-15 matrix, induces formation craze; and (ii) after the crazing initiated, the voids increase in size and elongate along the direction of the maximum principal tensile stress to form thin fibrils [68]. It is also evident in Fig. 14 that excessive stress-whitening occurred in the functionalized HNT-thiol nanocomposite, indicating the onset failure of the material.

The stress-whitening could also be correlated with a recoverable dilatational deformation just as the deformation was involved in fibril formation of the crazes [73]. As

\section{SN Applied Sciences}


proven in this work (Fig. 15), Merz et al. [74] also postulated that stress whitening was caused by scattered light from the microcracks and that void formation, which resulted from the opening of the cracks, permitted large strain. This helps with the energy absorption mechanism of the material.

\section{Conclusions}

In this work, the effects of the inclusion of pure and functionalized halloysite nanotubes on the critical stress intensity factor $\left(\mathrm{K}_{\mathrm{IC}}\right)$ and the critical strain energy release rate $\left(G_{1 C}\right)$ of the SC-15 epoxy were explored. The successful modification of HNTs, with an organosilane containing targeted functional groups (epoxy and thiol) was synthesized. These groups were selected to provide improved interfacial bonding between the HNTs and the SC-15 epoxy resin. The results of this study are summarized as follows:

- The addition of pure and functionalized HNT significantly improved the load-carrying capacity, the $\mathrm{K}_{\mathrm{I}}$, and the $\mathrm{G}_{\mathrm{IC}}$ of the SC-15 epoxy. Almost all specimens showed unstable crack propagation under a continuous loading condition, followed by a drastic load drop to zero after reaching the maximum. This implied the presence of linear elasticity and brittle behavior in the material except for 2\% HNT, 1\% HNT-epoxy, and 2\% HNT-thiol modified SC-15 epoxy.

- The inclusion of $2 \%$ of HNT-thiol exhibited the highest $\mathrm{K}_{\mathrm{IC}}$ improvement, $111 \%$, followed by the $2 \%$ pure HNT, $71 \%$, and $1 \%$ HNT-epoxy, $67 \%$. Similarly, inclusions of the $2 \%$ HNT-thiol, $2 \%$ HNT-epoxy, and 1\% HNT-epoxy enhanced the $G_{I C}$, by $276 \%, 182 \%$, and $413 \%$, respectively.

- SEM observations revealed that the HNT fillers in the matrix changed the toughness mechanics from smooth and low pseudo-ductile to several energy absorption mechanisms such as fibrils, crack bridging, crazing, microvoids, hackles, and stress whitening. The presence of these energy absorption mechanics resulted from the inclusion of HNTs supported the improvement of the fracture toughness and fracture energy.

Overall, the combined effect between the commercially available toughened SC-15 and HNT nanofillers are the most promising results which can give an alternative pathway for improving the fracture toughness of brittle thermoset materials that could be used for energy-absorbing devices and components in several applications such as vehicles, aeronautic, naval, personal protective equipment, and general construction.
Acknowledgments The authors acknowledge the Department of Chemistry and Biochemistry and the Department of Mechanical Engineering, Georgia Southern University. CF and MK acknowledge the university and the College Office of Undergraduate Research (COUR), Georgia Southern University for financial assistance. REU summer undergraduate ZM along with mentors' SL and EK greatly acknowledge the support of the National Science Foundation (Award Number: NSF-CHE (REU) 1757016). Thanks, are due to Mr. Andrew Diamanduros and Dr. Nathan Takas for instrumental assistance.

Complaince with ethical standards

Conflict of interest The authors declare that they have no conflict of interest.

\section{References}

1. Chen J, Kinloch AJ, Sprenger S, Taylor AC (2013) The mechanical properties and toughening mechanisms of an epoxy polymer modified with polysiloxane-based core-shell particles. Polymer 54(16):4276-4289

2. Zhao $M$, Meng L, Ma L, Ma L, Yang $X$, Huang $Y$, Ryu JE, Shankar A, Li T, Yan C, Guo Z (2018) Layer-by-layer grafting CNTs onto carbon fibers surface for enhancing the interfacial properties of epoxy resin composites. Compos Sci Technol 154:28-36

3. Wu Z, Cui H, Chen L, Jiang D, Weng L, Ma Y, Li X, Zhang X, Liu H, Wang N, Zhang J, Ma Y, Zhang M, Huang Y, Guo Z (2018) Interfacially reinforced unsaturated polyester carbon fiber composites with a vinyl ester-carbon nanotubes sizing agent. Compos Sci Technol 164:195-203

4. Kamar NT, Drzal LT (2016) Micron and nanostructured rubber toughened epoxy: a direct comparison of mechanical, thermomechanical and fracture properties. Polymer 92:114-124

5. Liang YL, Pearson RA (2010) The toughening mechanism in hybrid epoxy-silica-rubber nanocomposites (HESRNs). Polymer 51(21):4880-4890

6. Kumar B, Chitsiriphanit S, Sun CT (2011) Significance of K-dominance zone size and nonsingular stress field in brittle fracture. Eng Fract Mech 78(9):2042-2051

7. Quaresimin M, Salviato M, Zappalorto M (2012) Fracture and interlaminar properties of clay-modified epoxies and their glass reinforced laminates. Fract Damage Anal Design 81:80-93

8. Zamanian M, Mortezaei M, Salehnia B, Jam JE (2013) Fracture toughness of epoxy polymer modified with nanosilica particles: particle size effect. Eng Fract Mech 97:193-206

9. Leininger W, Wang X, Tangpong XW, McNea M (2012) Nanoscale structural and mechanical characterization of MWCNT-reinforced polymer composites. J Eng Mater Technol 134(2):021011

10. Wang X, Liu X, Yuan H, Liu H, Liu C, Li T, Yan C, Yan X, Shen C, Guo $Z$ (2018) Non-covalently functionalized graphene strengthened poly(vinyl alcohol). Mater Des 139:372-379

11. Kinloch AJ (2003) Toughening epoxy adhesives to meet today's challenges. MRS Bull 28(6):445-448

12. Drake RS, Egan DR, Murphy WT (1983) Elastomer-modified epoxy resins in coatings applications. In: Epoxy resin chemistry II, vol 221. American Chemical Society, Washington, DC, pp 1-20

13. Hsieh TH, Kinloch AJ, Masania K, Taylor AC, Sprenger S (2010) The mechanisms and mechanics of the toughening of epoxy polymers modified with silica nanoparticles. Polymer 51(26):6284-6294

14. Yee AF, Pearson RA (1986) Toughening mechanisms in elastomer-modified epoxies. J Mater Sci 21(7):2462-2474 
15. Bécu-Longuet $L$, Bonnet $A$, Pichot $C$, Sautereau $H$, Maazouz $A$ (1999) Epoxy networks toughened by core-Shell particles: influence of the particle structure and size on the rheological and mechanical properties. J Appl Polym Sci 72(6):849-858

16. Day RJ, Lovell PA, Wazzan AA (2001) Toughened carbon/epoxy composites made by using core/shell particles. Compos Sci Technol 61(1):41-56

17. Sue HJ, Meitin EIG, Pickelman DM, Bott CJ (1996) Fracture mechanisms in rigid core-shell particle modified high performance epoxies. Colloid Polym Sci 274(4):342-349

18. Sue HJ, Puckett PM, Bertram JL, Walker LL (2000) The network structure of epoxy systems and its relationship to toughness and toughenability. In: Toughening of plastics, vol 759. American Chemical Society, Washington, DC, pp 171-197

19. Argon AS, Cohen RE (2003) Toughenability of polymers. In Honour of lan Ward's 75th Birthday 44(19):6013-6032

20. Karger-Kocsis J, Friedrich K (1993) Microstructure-related fracture toughness and fatigue crack growth behaviour in toughened, anhydride-cured epoxy resins. Spec Issue Microphenomena Adv Compos 48(1):263-272

21. He Y, Yang S, Liu H, Shao Q, Chen Q, Lu C, Jiang Y, Liu C, Guo $Z$ (2018) Reinforced carbon fiber laminates with oriented carbon nanotube epoxy nanocomposites: magnetic field assisted alignment and cryogenic temperature mechanical properties. J Colloid Interface Sci 517:40-51

22. Wetzel B, Rosso P, Haupert F, Friedrich K (2006) Epoxy nanocomposites - fracture and toughening mechanisms. Fract Polym Compos Adhes 73(16):2375-2398

23. Ulus H, Kaybal HB, Eskizeybek V, Avcl A (2020) Halloysite nanotube reinforcement endows ameliorated fracture resistance of seawater aged basalt/epoxy composites. J Compos Mater 54(20):2761-2779

24. Ulus H, Kaybal HB, Eskizeybek V, Avcı A (2019) Enhanced salty water durability of halloysite nanotube reinforced epoxy/basalt fiber hybrid composites. Fibers Polym 20(10):2184-2199

25. Deng S, Zhang J, Ye L, Wu J (2008) Toughening epoxies with halloysite nanotubes. Polymer 49(23):5119-5127

26. Cavallaro G, Milioto S, Konnova S, Fakhrullina G, Akhatova F, Lazzara G, Fakhrullin R, Lvov Y (2020) Halloysite/Keratin nanocomposite for human hair photoprotection coating. ACS Appl Mater Interfaces 12(21):24348-24362

27. Lisuzzo L, Cavallaro G, Milioto S, Lazzara G (2020) Effects of halloysite content on the thermo-mechanical performances of composite bioplastics. Appl Clay Sci 185:105416

28. Cavallaro G, Lazzara G, Milioto S, Parisi F, Ruisi F (2017) Nanocomposites based on esterified colophony and halloysite clay nanotubes as consolidants for waterlogged archaeological woods. Cellulose 24(8):3367-3376

29. Guo F, Aryana S, Han Y, Jiao Y (2018) A review of the synthesis and applications of polymer-nanoclay composites. Appl Sci 8(9):1696

30. Nazir MS, Mohamad Kassim MH, Mohapatra L, Gilani MA, Raza MR, Majeed K (2016) Characteristic properties of nanoclays and characterization of nanoparticulates and nanocomposites. Springer, Singapore, pp 35-55

31. Lee SM, Tiwari D (2012) Organo and inorgano-organo-modified clays in the remediation of aqueous solutions: an overview. Appl Clay Sci 59-60:84-102

32. Peixoto AF, Fernandes AC, Pereira C, Pires J, Freire C (2016) Physicochemical characterization of organosilylated halloysite clay nanotubes. Microporous Mesoporous Mater 219:145-154

33. Tan D, Yuan P, Liu D, Du P (2016) Chapter 8 - Surface modifications of halloysite. In: Yuan P, Thill A, Bergaya F (eds) Developments in clay science, vol 7. Elsevier, Amsterdam, pp 167-201

34. Lazzara G, Cavallaro G, Panchal A, Fakhrullin R, Stavitskaya A, Vinokurov V, Lvov Y (2018) An assembly of organic-inorganic composites using halloysite clay nanotubes. Curr Opin Colloid Interface Sci 35:42-50

35. Bertolino V, Cavallaro G, Milioto S, Lazzara G (2020) Polysaccharides/Halloysite nanotubes for smart bionanocomposite materials. Carbohydr Polym 245:116502

36. Churchman GJ, Pasbakhsh P, Hillier S (2016) The rise and rise of halloysite. Clay Miner 51(3):303-308

37. Huang J, Tang ZH, Zhang XH, Guo BC (2016) Chapter 21 - Halloysite polymer nanocomposites. In: Yuan $P$, Thill A, Bergaya $F$ (eds) Developments in clay science, vol 7. Elsevier, Amsterdam, pp 509-553

38. Joussein $E$ (2016) Chapter 2 - Geology and mineralogy of nanosized tubular halloysite. In: Yuan P, Thill A, Bergaya F (eds) Developments in clay science, vol 7. Elsevier, Amsderdam, pp 12-48

39. Massaro M, Riela S, Cavallaro G, Gruttadauria M, Milioto S, Noto R, Lazzara $G$ (2014) Eco-friendly functionalization of natural halloysite clay nanotube with ionic liquids by microwave irradiation for Suzuki coupling reaction. J Organomet Chem 749:410-415

40. Cavallaro G, Chiappisi L, Pasbakhsh P, Gradzielski M, Lazzara G (2018) A structural comparison of halloysite nanotubes of different origin by Small-Angle Neutron Scattering (SANS) and Electric Birefringence. Appl Clay Sci 160:71-80

41. Srivastava S, Pandey A (2019) Mechanical behavior and thermal stability of ultrasonically synthesized halloysite-epoxy composite. Compos Commun 11(RSC Adv. 4, 2014):39-44

42. Domun $N$, Hadavinia $H$, Zhang $T$, Sainsbury $T$, Liaghat $G H$, Vahid $S$ (2015) Improving the fracture toughness and the strength of epoxy using nanomaterials - a review of the current status. Nanoscale 7(23):10294-10329

43. Su L, Zeng X, He H, Tao Q, Komarneni S (2017) Preparation of functionalized kaolinite/epoxy resin nanocomposites with enhanced thermal properties. Appl Clay Sci 148:103-108

44. Yu Z-Q, You S-L, Baier H (2012) Effect of organosilane coupling agents on microstructure and properties of nanosilica/epoxy composites. Polym Compos 33(9):1516-1524

45. Jana S, Das S (2014) Development of novel inorganic-organic hybrid nanocomposites as a recyclable adsorbent and catalyst. RSC Adv 4(65):34435-34442

46. Carli LN, Daitx TS, Soares GV, Crespo JS, Mauler RS (2014) The effects of silane coupling agents on the properties of PHBV/ halloysite nanocomposites. Appl Clay Sci 87:311-319

47. Yuan P, Southon PD, Liu Z, Green MER, Hook JM, Antill SJ, Kepert CJ (2008) Functionalization of halloysite clay nanotubes by grafting with $\gamma$-aminopropyltriethoxysilane. J Phys Chem C 112(40):15742-15751

48. Barrientos-Ramírez $\mathrm{S}$, de Oca-Ramírez GM, Ramos-Fernández EV, Sepúlveda-Escribano A, Pastor-Blas MM, González-Montiel A (2011) Surface modification of natural halloysite clay nanotubes with aminosilanes. Application as catalyst supports in the atom transfer radical polymerization of methyl methacrylate. Appl Catal A Gen 406(1):22-33

49. Abeywardena SBY, Perera S, Nalin de Silva KM, Tissera NP (2017) A facile method to modify bentonite nanoclay with silane. Int Nano Lett 7(3):237-241

50. Joussein E, Petit S, Churchman J, Theng B, Righi D, Delvaux B (2005) Halloysite clay minerals - a review. Clay Miner 40(4):383-426

51. Khajehpour M, Gelves GA, Sundararaj U (2015) Modification of montmorillonite with alkyl silanes and fluorosurfactant for clay/fluoroelastomer (FKM) nanocomposites. Clay Clay Miner 63(1):1-14

52. Rachini A, Le Troedec M, Peyratout C, Smith A (2012) Chemical modification of hemp fibers by silane coupling agents. J Appl Polym Sci 123(1):601-610

53. Shao L, Wang X, Yang B, Wang Q, Tian Q, Ji Z, Zhang J (2017) A highly sensitive ascorbic acid sensor based on hierarchical 
polyaniline coated halloysite nanotubes prepared by electrophoretic deposition. Electrochim Acta 255:286-297

54. Lvov Y, Wang W, Zhang L, Fakhrullin R (2016) Halloysite clay nanotubes for loading and sustained release of functional compounds. Adv Mater 28(6):1227-1250

55. Duarte, H. A., Chapter 14 - Molecular simulation of nanosized tubular clay minerals. In Developments in clay science, Yuan, P., Thill, A., Bergaya, F., Eds. Elsevier, Amsterdam: 2016; Vol. 7, pp. 331-359

56. Massaro M, Colletti CG, Lazzara G, Milioto S, Noto R, Riela S (2017) Halloysite nanotubes as support for metal-based catalysts. J Mater Chem A 5(26):13276-13293

57. Sun P, Liu G, Lv D, Dong X, Wu J, Wang D (2016) Simultaneous improvement in strength, toughness, and thermal stability of epoxy/halloysite nanotubes composites by interfacial modification. J Appl Polym Sci 133(13):43249

58. Massaro M, Colletti CG, Fiore B, La Parola V, Lazzara G, Guernelli S, Zaccheroni N, Riela S (2019) Gold nanoparticles stabilized by modified halloysite nanotubes for catalytic applications. Appl Organomet Chem 33(3):e4665

59. Levis SR, Deasy PB (2002) Characterisation of halloysite for use as a microtubular drug delivery system. Int J Pharm 243(1):125-134

60. Mei D, Zhang B, Liu R, Zhang Y, Liu J (2011) Preparation of capric acid/halloysite nanotube composite as form-stable phase change material for thermal energy storage. Sol Energy Mater Sol Cells 95(10):2772-2777

61. Almasri DA, Saleh NB, Atieh MA, McKay G, Ahzi S (2019) Adsorption of phosphate on iron oxide doped halloysite nanotubes. Sci Rep 9(1):3232

62. Deng S, Zhang J, Ye L (2009) Halloysite-epoxy nanocomposites with improved particle dispersion through ball mill homogenisation and chemical treatments. The Sixteenth international conference on composite materials with regular papers. 69(14):2497-2505

63. Yah WO, Takahara A, Lvov YM (2012) Selective modification of halloysite lumen with octadecylphosphonic acid: new inorganic tubular micelle. J Am Chem Soc 134(3):1853-1859

64. Rooj S, Das A, Thakur V, Mahaling RN, Bhowmick AK, Heinrich G (2010) Preparation and properties of natural nanocomposites based on natural rubber and naturally occurring halloysite nanotubes. Desig Nanomater Nanostruc 31(4):2151-2156

65. Albdiry MT, Yousif BF (2014) Role of silanized halloysite nanotubes on structural, mechanical properties and fracture toughness of thermoset nanocomposites. Mater Des 57:279-288

66. Wang ML, McAninch IM, Scala JJL (2011) In Materials characterization of high-temperature epoxy resins: SC-79 and SC 15/SC-79 blend

67. Anderson TL (1991) Fracture mechanics - fundamentals and applications. 92:40200

68. Kim BC, Park SW, Lee DG (2008) Fracture toughness of the nanoparticle reinforced epoxy composite. Fourteenth international conference on composite structures 86(1):69-77

69. Zappalorto M, Salviato M, Quaresimin M (2012) A multiscale model to describe nanocomposite fracture toughness enhancement by the plastic yielding of nanovoids. Compos Sci Technol 72(14):1683-1691

70. Wang J, Zhang $X$, Jiang L, Qiao J (2019) Advances in toughened polymer materials by structured rubber particles. Prog Polym Sci 98:101160

71. Opelt CV, Becker D, Lepienski CM, Coelho LAF (2015) Reinforcement and toughening mechanisms in polymer nanocomposites - carbon nanotubes and aluminum oxide. Compos Part B 75:119-126

72. Charlie RB, Ashok C (2002) Failure analysis of engineering materials. McGraw-Hill Education, New York

73. Huang Y, Hunston DL, Kinloch AJ, Riew CK (1993) Mechanisms of toughening thermoset resins. In: Toughened plastics I, vol 233. American Chemical Society, Washington, DC, pp 1-35

74. Merz EH, Claver GC, Baer M (1956) Studies on heterogeneous polymeric systems. J Polym Sci 22(101):325-341

Publisher's Note Springer Nature remains neutral with regard to jurisdictional claims in published maps and institutional affiliations. 